NASA/TM-2013-216571

\title{
Preparation for Scaling Studies of Ice-Crystal Icing at the NRC Research Altitude Test Facility
}

Peter M. Struk and Timothy M. Bencic

Glenn Research Center, Cleveland, Ohio

Jen-Ching Tsao

Ohio Aerospace Institute, Brook Park, Ohio

Dan Fuleki and Daniel C. Knezevici

National Research Council of Canada, Ottawa, Ontario, Canada 


\section{NASA STI Program . . . in Profile}

Since its founding, NASA has been dedicated to the advancement of aeronautics and space science. The NASA Scientific and Technical Information (STI) program plays a key part in helping NASA maintain this important role.

The NASA STI Program operates under the auspices of the Agency Chief Information Officer. It collects, organizes, provides for archiving, and disseminates NASA's STI. The NASA STI program provides access to the NASA Aeronautics and Space Database and its public interface, the NASA Technical Reports Server, thus providing one of the largest collections of aeronautical and space science STI in the world. Results are published in both non-NASA channels and by NASA in the NASA STI Report Series, which includes the following report types:

- TECHNICAL PUBLICATION. Reports of completed research or a major significant phase of research that present the results of NASA programs and include extensive data or theoretical analysis. Includes compilations of significant scientific and technical data and information deemed to be of continuing reference value. NASA counterpart of peer-reviewed formal professional papers but has less stringent limitations on manuscript length and extent of graphic presentations.

- TECHNICAL MEMORANDUM. Scientific and technical findings that are preliminary or of specialized interest, e.g., quick release reports, working papers, and bibliographies that contain minimal annotation. Does not contain extensive analysis.

- CONTRACTOR REPORT. Scientific and technical findings by NASA-sponsored contractors and grantees.
- CONFERENCE PUBLICATION. Collected papers from scientific and technical conferences, symposia, seminars, or other meetings sponsored or cosponsored by NASA.

- SPECIAL PUBLICATION. Scientific, technical, or historical information from NASA programs, projects, and missions, often concerned with subjects having substantial public interest.

- TECHNICAL TRANSLATION. Englishlanguage translations of foreign scientific and technical material pertinent to NASA's mission.

Specialized services also include creating custom thesauri, building customized databases, organizing and publishing research results.

For more information about the NASA STI program, see the following:

- Access the NASA STI program home page at http://www.sti.nasa.gov

- E-mail your question to help@sti.nasa.gov

- Fax your question to the NASA STI Information Desk at 443-757-5803

- Phone the NASA STI Information Desk at 443-757-5802

- Write to: STI Information Desk NASA Center for AeroSpace Information 7115 Standard Drive Hanover, MD 21076-1320 
NASA/TM-2013-216571

AIAA-2013-2675

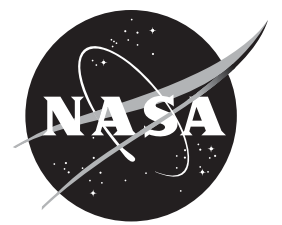

\section{Preparation for Scaling Studies of Ice-Crystal Icing at the NRC Research Altitude Test Facility}

Peter M. Struk and Timothy M. Bencic

Glenn Research Center, Cleveland, Ohio

Jen-Ching Tsao

Ohio Aerospace Institute, Brook Park, Ohio

Dan Fuleki and Daniel C. Knezevici

National Research Council of Canada, Ottawa, Ontario, Canada

Prepared for the

5th Atmospheric and Space Environments Conference

sponsored by the American Institute of Aeronautics and Astronautics

San Diego, California, June 24-27, 2013

National Aeronautics and

Space Administration

Glenn Research Center

Cleveland, Ohio 44135 


\section{Acknowledgments}

This work was performed under an International Agreement between NASA and the National Research Council of Canada. The authors wish to acknowledge the financial support for this work by the Atmospheric Environment Safety Technologies (AEST) project under NASA's Aviation Safety Program, the National Research Council, the Federal Aviation Administration, and Transport Canada. Special thanks are extended to Dr. Ron Colantonio, Mr. Jim MacLeod, and Mr. Thomas Bond for their support of the work. Finally, the authors would like to thank Mr. Chris Lynch for his excellent imaging work during the experiment.

Trade names and trademarks are used in this report for identification only. Their usage does not constitute an official endorsement, either expressed or implied, by the National Aeronautics and Space Administration.

Level of Review: This material has been technically reviewed by technical management.

Available from

NASA Center for Aerospace Information 7115 Standard Drive

Hanover, MD 21076-1320
National Technical Information Service 5301 Shawnee Road Alexandria, VA 22312

Available electronically at http://www.sti.nasa.gov 


\title{
Preparation for Scaling Studies of Ice-Crystal Icing at the NRC Research Altitude Test Facility
}

\author{
Peter M. Struk and Timothy M. Bencic \\ National Aeronautics and Space Administration \\ Glenn Research Center \\ Cleveland, Ohio 44135 \\ Jen-Ching Tsao \\ Ohio Aerospace Institute \\ Brook Park, Ohio 44142 \\ Dan Fuleki and Daniel C. Knezevici \\ National Research Council of Canada \\ Ottawa, Ontario, Canada K1A 0R6
}

\begin{abstract}
This paper describes preparation for ice-crystal icing scaling work utilizing the Cascade rig at the National Research Council (NRC) of Canada's Research Altitude Test Facility (RATFac). Tests supporting this work and continuing the collaboration between National Aeronautics and Space Administration (NASA) and NRC on ice-crystal icing took place between March 26 and April 11, 2012. The focus was on several aspects but emphasized characterization of the RATFac cloud including watercontent and test-section uniformity as well as particle-size measurements. Water content measurements utilized the Science Engineering Associates (SEA) Multi-Element probe while cloud uniformity measurements used light scattering from particles passing through a laser sheet. Finally, particle sizespectra measurements used two developmental shadowgraph systems. Details of these measurements as well as selected results are presented. An analysis algorithm is presented that interprets mixed-phase measurements from the SEA probe using calibrations from individual water and ice clouds. The analysis is applied to one mixed-phase data set generated with a glaciated cloud combined with supplemental water. The test section temperature was below freezing to prevent the natural melting of the ice crystals. The analysis algorithm relies on the measurement of test-section humidity to account for cloud evaporation. Results of the cloud-uniformity measurements using scattered light suggest that the measured intensity is a good first-order measurement of concentration, independent of the water phase. Steeper intensity gradients across the test section are observed with increasing ice-water content. For particle-size measurements, both shadowgraphy methods provide high-quality images of the particles. These images will be processed to establish particle-size distributions and morphology characteristics. The results from this work will help guide future ice-crystal icing research including scaling studies.
\end{abstract}

\section{Nomenclature}

$\mathrm{A}_{\mathrm{C}}$ $\mathrm{D}_{\mathrm{V}} 10, \mathrm{D}_{\mathrm{V}} 50, \mathrm{D}_{\mathrm{V}} 90$

FOV

fps

IWC

LED

LWC cross sectional area of test section $\left(0.0337 \mathrm{~m}^{2}\right)$

particle diameter below which the cumulative particle vol. is 10,50 , or 90 percent of the total sample vol.

field of view

frames per second

ice water content $\left(\mathrm{g} / \mathrm{m}^{3}\right)$

light emitting diode

liquid water content $\left(\mathrm{g} / \mathrm{m}^{3}\right)$ 


\begin{tabular}{|c|c|}
\hline$\dot{\mathrm{m}}_{\ell}$ & mass flow rate of supplemental liquid water $(\mathrm{g} / \mathrm{s})$ \\
\hline$\dot{\mathrm{m}}_{\mathrm{air}, \mathrm{cj}}$ & mass flow rate of air from cold jet which delivers ice crystals (g/s) \\
\hline$\dot{\mathrm{m}}_{\mathrm{air}, \mathrm{ea}}$ & $\begin{array}{l}\text { mass flow rate of air entrained from surroundings of the warm side of RATFac into } \\
\text { the test section }(\mathrm{g} / \mathrm{s})\end{array}$ \\
\hline$\dot{\mathrm{m}}_{\mathrm{i}}$ & mass feed rate of ice $(\mathrm{g} / \mathrm{s})$ \\
\hline MMD & mass median diameter $(\mathrm{m})$ \\
\hline MVD & median volumetric diameter $(\mathrm{m})$, used interchangeably with $\mathrm{D}_{\mathrm{v}} 50$ \\
\hline $\mathrm{P}_{0}$ & total pressure $(\mathrm{kPa})$ \\
\hline PIV & particle imaging velocimetry \\
\hline$\dot{\mathrm{q}}_{\text {air }}=\mathrm{V}_{\infty} \cdot \mathrm{A}_{\mathrm{C}}$ & volumetric flow rate of air at test section $\left(\mathrm{m}^{3} / \mathrm{s}\right)$ \\
\hline RATFac & Research Altitude Test Facility \\
\hline RH & relative humidity ( percent) \\
\hline ROI & region of interest \\
\hline SEA & Science Engineering Associates, Inc. \\
\hline $\mathrm{SH}, \mathrm{SH}_{\mathrm{off}}, \mathrm{SH}_{\mathrm{on}}$ & $\begin{array}{l}\text { specific humidity }\left(\mathrm{g}_{\mathrm{H} 2 \mathrm{O}} / \mathrm{kg}_{\mathrm{dry}} \text { air }\right) \text {, on/off denotes measurement with cloud on/off, } \\
\text { respectively. }\end{array}$ \\
\hline TAT & total air temperature $\left({ }^{\circ} \mathrm{C}\right)$ \\
\hline TWC & total water content $\left(\mathrm{g} / \mathrm{m}^{3}\right) \mathrm{TWC} \equiv \mathrm{LWC}+\mathrm{IWC}$ \\
\hline $\mathrm{V}_{\infty}$ & test-section centerline velocity $(\mathrm{m} / \mathrm{s})$ \\
\hline$\rho_{\text {air }}$ & air density $\left(\mathrm{kg} / \mathrm{m}^{3}\right)$ \\
\hline \multicolumn{2}{|c|}{ Subscripts and Superscripts for LWC, IWC, or TWC } \\
\hline e & evaporated \\
\hline FR & false response on LWC elements due to ice crystals \\
\hline $\mathrm{i}$ & injected \\
\hline $\mathrm{m}$ & measured \\
\hline $\mathrm{s}$ & sublimated \\
\hline $\mathrm{t}$ & test section \\
\hline 2 & $2.1 \mathrm{~mm}$ diameter element \\
\hline 0.5 & $0.5 \mathrm{~mm}$ diameter element \\
\hline$*$ & calculated value using the mixed-phase hypothesis \\
\hline
\end{tabular}

\subsection{Introduction}

Due to numerous engine power-loss events associated with high-altitude convective weather, potential ice accretion within an engine due to ice-crystal ingestion is being investigated collaboratively by National Aeronautics and Space Administration (NASA) and the National Research Council (NRC) of Canada with additional sponsorship by both the Federal Aviation Administration and Transport Canada. These investigations examine the physical mechanisms of ice accretion on surfaces exposed to ice-crystal and mixed-phase conditions, similar to those believed to exist in core compressor regions of jet engines. The investigations are largely experimental using the NRC Research Altitude Test Facility (RATFac) and designed to test hypotheses of engine-core icing processes including particle impact, phase change, accretion, erosion, etc.

Early investigations from these collaborative efforts suggest that increasing altitude (i.e., decreasing pressure) plays a role in ice-crystal icing as it enhances evaporative cooling and lowers the wet-bulb temperature (Refs. 1 and 2). It is desirable to see if equivalent icing conditions could be realized near sea- 
level which can be advantageous for testing from a cost perspective as altitude facilities can be costly to operate. Altitude scaling (Ref. 3) for ice-crystal accretion is a condition scaling method to determine the scaled test conditions (icing near sea level) that produce the same non-dimensional ice accretion result as the reference condition (i.e., icing at altitude). To date, only limited testing has been performed to understand if such altitude scaling can be realized. In addition, current scaling methods for super-cooled water droplets need to be extended to include the ice-crystal only and mixed-phase regime. Therefore, further work both in terms of theoretical development and experimental validation is required.

NASA and NRC are currently working on scaling methods for ice-crystal icing. In preparation for future testing at RATFac dedicated to scaling, a test entry took place at the RATFac from March 26 to April 11, 2012. This 2012 test entry had three primary objectives broadly categorized under the following topic areas: (1) cloud characterization, (2) scaling model developments, and (3) ice-shape measurement. The emphasis of this paper is on the first objective, cloud-characterization, and includes results from water content, cloud uniformity, and particle size-spectra measurements. A complimentary paper in this conference (Ref. 4) reports some early progress by NRC on altitude scaling with ice-crystal accretion.

\subsection{Background}

The first series of experiments by the NRC and NASA group was conducted at RATFac in 2010 (Ref. 1). These experiments utilized a single wedge-type airfoil designed to facilitate fundamental studies while retaining critical features of a compressor stator blade or guide vane. The airfoil was placed in a small Cascade wind tunnel located within RATFac and icing tests were performed at various Mach numbers, altitudes, temperatures, as well as ice and liquid water contents. The ice appeared well adhered to the surface in tests at higher altitude (lower pressure) and, in several cases, showed continuous leadingedge ice growth to a thickness greater than $15 \mathrm{~mm}$ in $3 \mathrm{~min}$. Such deposits were not observed in the lower-altitude (higher-pressure) tests, where the accretions were limited to a small area around the leading edge. The icing behavior at high and low pressure appeared to correlate with the wet-bulb temperature, which was estimated to be above $0{ }^{\circ} \mathrm{C}$ in the lower altitude tests and below $0{ }^{\circ} \mathrm{C}$ in tests at higher altitude, the latter enhanced by more evaporative cooling of water.

Shortly after the 2010 test entry, the NRC facility added the capability to control the humidity in the wind tunnel. This allowed the humidity content to be increased from a minimum value of $-50{ }^{\circ} \mathrm{C}$ dew point. Increasing humidity also increases the air wet-bulb temperature up to the limit of 100 percent relative humidity $(\mathrm{RH})$ in the test section when the wet bulb temperature equals the surrounding air temperature. At RH lower than 100 percent, the air wet-bulb temperature is less than the surrounding dry-air temperature due to evaporative cooling of the water. It is believed that both the droplets and regions of the airfoil can approach the wet-bulb temperature under certain conditions. After these initial tests, a hypothesis was posed that when the wet-bulb temperature is below freezing then a well-adhered type of icing can occur.

In 2011, a second series of tests was conducted to examine the effects of wet-bulb temperature on the icing characteristics. A sub-set of those results was reported in 2012 (Ref. 2) which directly examined the wet-bulb temperature as an icing indicator. These tests independently varied temperature and humidity to

achieve the same wet-bulb temperatures which showed that icing occurred when the wet-bulb temperature is below-freezing. These results confirmed that wet-bulb temperature is a good indicator of the potential for icing. Finally, it is important to point out that ice accumulation was observed with wet-bulb temperatures above freezing when the ice concentrations were quite high.

Although wet-bulb temperature may be a good indicator for the icing potential, other well-established factors also influence icing. These include factors such as the droplet collection efficiency (governed by geometry, flowfield, particle size, etc.) and water loading and state. Regarding the water state, all previous studies show that the presence of liquid water is required for ice accretion to occur. Furthermore, Mason et al. (Ref. 5) hypothesized that there is an optimum ratio of water to ice that maximizes ice accretion for a given water loading. Experimentally, the liquid water can come from the melting of ice crystals or be added separately. These other factors are considered in the present studies, as well. 
The NRC RATFac uses a hot-wire probe, the Science Engineering Associates (SEA) multi-wire probe, model WCM-2000, to determine both the liquid and total water content. The probe has three elements: one element (2-mm half-pipe cross-section) for measuring the total water content (TWC) and two additional elements (2.1- and 0.5 -mm diameter cylinders) for measuring the liquid water content (LWC). Data from both the 2010 and 2011 tests indicate that the TWC measurement in the presence of ice is significantly lower than the expected TWC based on bulk mass measurements of ice injected into the tunnel. Also, the TWC-element response at higher injected IWC showed a periodic response which was not understood at the time of the testing but was later confirmed with the manufacturer to be related to WCM-2000 controller settings. To date, the LWC elements have only been calibrated for use in pure liquid conditions and it is not clear if the LWC measurement in mixed-phase condition accurately represents liquid water content of the mixed phase. The 2012 test entry dedicated a significant portion of the test time to begin characterizing the SEA Multi-Element probe in mixed-phased conditions.

For experiments in RATFac, the typically reported IWC and LWC values are bulk-averaged values and are calibrated using the SEA Multi-Element probe prior to a test. These values, subsequently called $\mathrm{IWC}_{\mathrm{i}}$ or $\mathrm{LWC}_{\mathrm{i}}$ in this paper where the subscript denotes the injected bulk value, are calculated by dividing the mass feed rate (set point) of ice and/or water by the volumetric flow rate of air, $\dot{\mathrm{q}}_{\text {air }}$, through the test section. The $\dot{\mathrm{q}}_{\text {air }}$ is calculated by taking the measured velocity at the centerline of the test section (under cloud-off conditions) and multiplying by the cross-sectional area of the test section.

The uniformity of the ice or water distribution across the test section is important to quantify for all test conditions. NRC has previously reported some uniformity results using a process in which they traverse the SEA Multi-Element probe across the test section. These results provided several discrete point measurements across the test section. To supplement those results, NASA examined another technique during the 2012 test entry which utilized a laser-sheet positioned across the test section to provide additional uniformity information. As particles passed through the laser sheet, some light would be forward-scattered and would be detected by a downstream imager (not in the flow). This technique was previously used at the NASA Icing Research Tunnel (Ref. 6) to help visualize the uniformity of a liquid-water cloud.

During the 2011 test entry, the RATFac included a new probe capable of measuring total air temperature (TAT) and humidity at the test section in both dry and wet conditions. This probe, hereafter referred to as the TAT-RH probe, was mounted approximately $51 \mathrm{~mm}$ from the base of the tunnel and in the same plane as the SEA Multi-Element probe. During testing, measurements from the TAT-RH probe indicated a drop in stagnation air temperature and an increase in test section humidity as the cloud was turned on. This suggests that energy is transferred from the air to the cloud causing ice particles to melt and/or sublimate, as well as liquid-water evaporation. This significant observation implies that the dry conditions, measured prior to the start of an icing test, do not accurately represent the conditions near the test article while the cloud is on. Later in 2011, NRC added the capability to traverse the TAT-RH probe vertically along the centerline of the test section. In the current 2012 test campaign, measurements at various locations in the flow were made by the TAT-RH probe as well as the existing total pressure and temperature probe $\left(\mathrm{P}_{0}\right.$ and TAT probe) which can only be used in dry conditions. Data comparing the TAT-RH and $\mathrm{P}_{0}$ and TAT probe measurements is available but is not presented in this paper.

Another key parameter in studying icing phenomenon is the particle-size distribution. At RATFac, an ice-particle cloud is generated by a grinding system with different configurations to vary the median mass diameter (MMD) of the cloud. A shadowgraph particle sizing method using PIV hardware (Ref. 7) is currently being used by NRC to determine the size distribution of various clouds. Preliminary results suggest that the "small" grinder configuration yielded a cloud MMD of 50 to $100 \mu \mathrm{m}$, while the "large" configuration generated an MMD of 200 to $300 \mu \mathrm{m}$ (Ref. 8). This early work used measurements upstream of the bellmouth. During the 2012 test entry, the NRC PIV system was setup to measure particle sizes at the test section for the first time. Furthermore, NASA experimented with a similar shadowgraph technique using a high-speed camera coupled with a pulsed light-emitting diode (LED) which measured particles just downstream of the ice-ejector duct. This offered the possibility to discriminate particle phase by making two sets of measurements at different downstream locations. 


\subsection{Cloud Characterization}

During testing, ice particles, supplemental liquid water, or both are injected into the Cascade test rig. A schematic representation of the test setup is shown in Figure 1. The injected mass feed rates of the ice and flow rates of supplemental liquid water content are denoted as $\dot{\mathrm{m}}_{\mathrm{i}}, \dot{\mathrm{m}}_{\ell}$, respectively. The supplemental liquid mass can be injected using up to 8 nozzles. For this testing, typically 2 or 4 nozzles were used. The air mass flow at the test section is drawn by downstream compressors and is comprised of air from a cold jet, $\dot{\mathrm{m}}_{\text {air,CJ}}$, with the remainder of the air being entrained from the surroundings, $\dot{\mathrm{m}}_{\text {air,ea }}$, on the warm side of the facility. The humidity at the test section can be varied by changing the humidity of the entrained air and can range from a minimum value of $-50{ }^{\circ} \mathrm{C}$ dew point to higher values using a humidity injection system. The RATFac measures specific humidity, $\mathrm{SH}$, at the test section continually both with the cloud off and on. The humidity at the test section increases when the cloud is turned on indicating that sublimation or evaporation is occurring as the ice and water particles traverse from the injectors to the nozzles.

An important technical requirement for this research is being able to quantify the cloud conditions at the test section based on injected values for different flow and ambient conditions. The mass concentrations of ice and supplemental liquid water at the test section are denoted with the subscript $t$ (e.g., $\mathrm{IWC}_{\mathrm{t}}$ and $\mathrm{LWC}_{\mathrm{t}}$ ). For clouds with just water sprays, the $\mathrm{LWC}_{\mathrm{t}}$ can be calculated from the injected mass flow rates and specific humidity measurements as shown in Equation (1). Here, $\mathrm{LWC}_{\mathrm{i}}$ is equal to the injected $\dot{\mathrm{m}}_{\ell}$ divided by the volumetric flow rate of air, $\dot{\mathrm{q}}_{\mathrm{air}}$, at the test section, as shown in Equation (2). The $\mathrm{LWC}_{\mathrm{i}}$ is considered the test-section average value assuming no evaporation. The mass concentration of water vapor gained at the test section due to evaporation is denoted as $\mathrm{LWC}_{\mathrm{t}, \mathrm{e}}$ as calculated in Equation (3). Note that Equations (1) to (3) assume uniform mixing at the test section and other modes of mass loss (e.g., splashing/accretion on the windows or other areas of the facility upstream of the test section) are negligibly small.

$$
\begin{gathered}
\mathrm{LWC}_{\mathrm{t}}=\mathrm{LWC}_{\mathrm{i}}-\mathrm{LWC}_{\mathrm{t}, \mathrm{e}} \\
\mathrm{LWC}_{\mathrm{i}}=\frac{\mathrm{m}_{\ell}}{\dot{\mathrm{q}}_{\mathrm{air}}} \\
\mathrm{LWC}_{\mathrm{t}, \mathrm{e}}=\rho_{\text {air }}\left(\mathrm{SH}_{\mathrm{on}}-\mathrm{SH}_{\mathrm{off}}\right)
\end{gathered}
$$

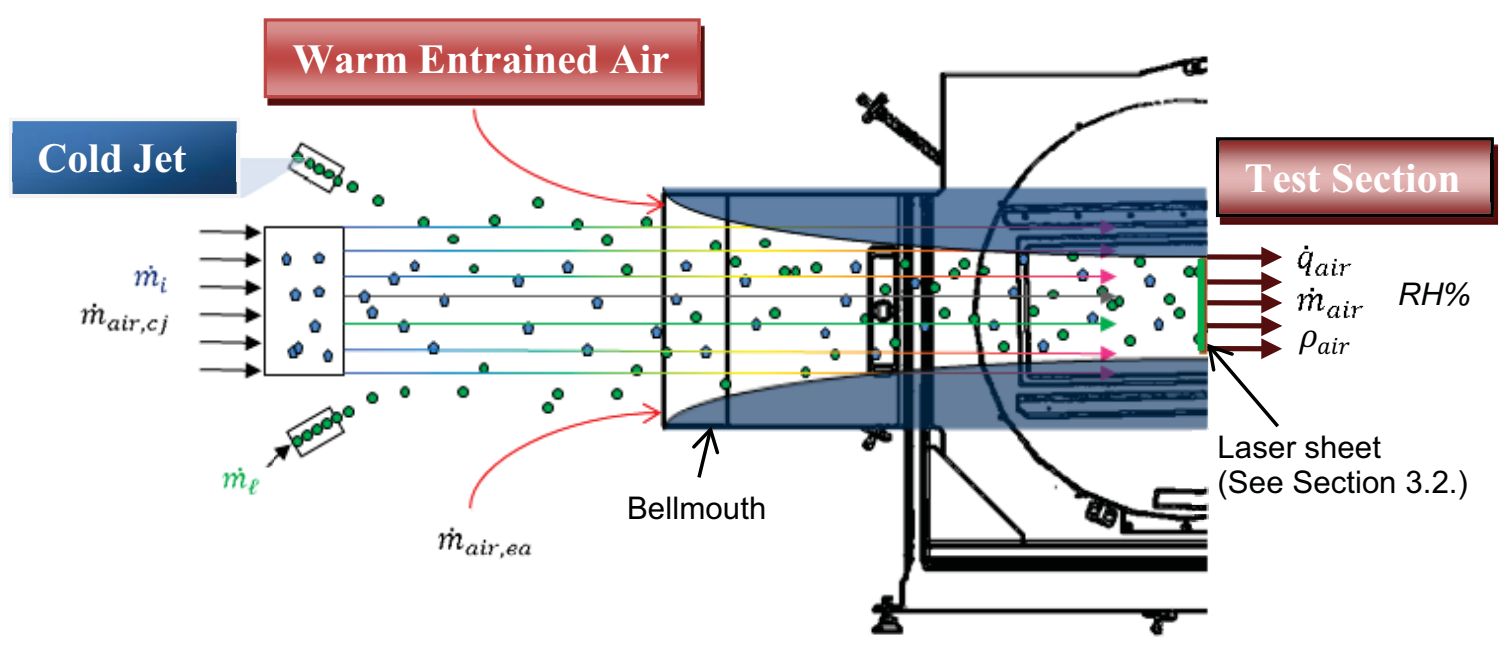

Figure 1.-Schematic representation of the icing test configuration at RATFac where the Cascade rig is placed in the warm section and the test-section flow is drawn by downstream compressors (not shown) and is comprised of a cold jet mixed with warm entrained air. 
For fully-glaciated clouds at temperatures below freezing, the values for $\mathrm{IWC}_{\mathrm{t}}$ can be calculated similarly to the liquid-water-only sprays as shown in Equation (4). Here, $\mathrm{IWC}_{\mathrm{i}}$ is the average ice-particlemass concentration at the test section assuming no sublimation, as shown in Equation (5), and $\mathrm{IWC}_{\mathrm{t}, \mathrm{s}}$ is the vapor-mass concentration gained due to ice particle sublimation from injection to the test section, as shown in Equation (6). In this case, ice is assumed only to sublimate due to the cold conditions. Again, uniform mixing at the test section is assumed.

$$
\begin{gathered}
\mathrm{IWC}_{\mathrm{t}}=\mathrm{IWC}_{\mathrm{i}}-\mathrm{IWC}_{\mathrm{t}, \mathrm{s}} \\
\mathrm{IWC}_{\mathrm{i}}=\frac{\dot{\mathrm{m}}_{\mathrm{I}}}{\dot{\mathrm{q}}_{\mathrm{air}}} \\
\mathrm{IWC}_{\mathrm{t}, \mathrm{s}}=\rho_{\mathrm{air}}\left(\mathrm{SH}_{\mathrm{on}}-\mathrm{SH}_{\mathrm{off}}\right)
\end{gathered}
$$

Finally, if both ice and supplemental water are injected, then the $\mathrm{TWC}_{\mathrm{t}}$ at the test section, as shown in Equation (7), can be calculated from the injected total water content, $\mathrm{TWC}_{\mathrm{i}}$ as calculated by Equation (8), and subtracting the amount of mass concentration (assuming uniform mixing) that sublimated or evaporated, $\mathrm{TWC}_{\mathrm{t}, \mathrm{s}+\mathrm{e}}$ as calculated by Equation (9). Here, $\mathrm{TWC}_{\mathrm{i}}$ is the combined ice and liquid water mass-concentration averaged across the test section assuming no sublimation and evaporation. The vapormass concentration gain at the test section, $\mathrm{TWC}_{\mathrm{t}, \mathrm{s}+\mathrm{e}}$, comes from both sublimation and evaporation as the ice and liquid water flow, respectively. Note that the portion of the vapor increase due to ice sublimation versus liquid water evaporation cannot be separately measured in this mixed-phase cloud. However, a later section will describe an algorithm to deduce the individual $\mathrm{IWC}_{\mathrm{t}}$ and $\mathrm{LWC}_{\mathrm{t}}$ at the test section under mixed phase conditions.

$$
\begin{gathered}
\mathrm{TWC}_{\mathrm{t}}=\mathrm{TWC}_{\mathrm{i}}-\mathrm{TWC}_{\mathrm{t}, \mathrm{s}+\mathrm{e}} \\
\mathrm{TWC}_{\mathrm{i}}=\frac{\dot{\mathrm{m}}_{\mathrm{t}}+\mathrm{m}_{\ell}}{\dot{\mathrm{q}}_{\mathrm{air}}} \\
\mathrm{TWC}_{\mathrm{t}, \mathrm{s}+\mathrm{e}}=\rho_{\mathrm{air}}\left(\mathrm{SH}_{\mathrm{on}}-\mathrm{SH}_{\mathrm{off}}\right)
\end{gathered}
$$

The aspects examined in this study include (A) measurements of LWC and TWC, (B) cloud uniformity, and $(\mathrm{C})$ particle spectra.

\subsection{SEA Multi-Element Probe Measurements}

The total and liquid water contents at the test section are measured using the SEA multi-wire probe (Ref. 9). The TWC is measured using a hot-wire element with a half-pipe cross section where the concave portion is facing the incoming flow. A basic premise for the half-pipe element is that it captures and completely vaporizes all of the incoming ice and water particles while maintaining the element at a prescribed temperature of $140{ }^{\circ} \mathrm{C}$. The power required to maintain the element at $140{ }^{\circ} \mathrm{C}$ is related to the impinging water and ice. While the multi-wire half-pipe measurement corresponds well with blade measurements in Appendix C supercooled liquid (Ref. 10), previous studies in ice-crystals (Ref. 11) have measured values lower than the expected values of TWC. One factor is that the conversion from power to TWC does not account for the heat of fusion for ice. However, this factor is small and would lower the calculated TWC for a given power measurement. Rather, it is speculated that the under reading in ice crystals is due to ice-particle splashing, bouncing, or otherwise flowing away prior to being vaporized by the element. Sections below further explore the TWC measurement in ice crystals presenting some quantitative results and probe imaging.

The LWC is measured by two heated elements with a cylindrical cross section of 0.5 and $2.1 \mathrm{~mm}$ in diameter. Measurements from those elements are denoted as $\mathrm{LWC}_{\mathrm{m}, 0.5}$ and $\mathrm{LWC}_{\mathrm{m}, 2}$, respectively. The power required to maintain the element at $140{ }^{\circ} \mathrm{C}$ is related to the impinging liquid water assuming that 
all LWC that contacts the wire evaporates. Data from the development of the SEA multi-wire probe (Ref. 9) suggests that the different diameter cylinders, just as with the TWC measurement, do not respond identically to liquid clouds of different MVD. In fact, the original intent of the multiple-diameter cylinders was to discriminate between clouds of different droplet sizes owing to the different collection efficiencies of the cylindrical wires. In pure ice-crystal conditions, both manufacturer testing as reported in the owner's manual and an internal NASA study (Ref. 12) have indicated that the LWC elements have a false response to the presence of ice crystals. This is expected as some of the impinging ice would melt and cool the heated wire. In mixed phase, it is not known if the LWC elements will accurately differentiate between liquid and ice.

During the 2012 test entry, a number of tests examined the SEA multi-wire probe measurements to pure IWC and LWC sprays as well as combined IWC and supplemental LWC sprays. The ice-particle clouds used the "small" size ice grinder configuration of the RATFac (Ref. 8). The tests were conducted at a total air temperature below freezing of approximately $-1{ }^{\circ} \mathrm{C}$ to eliminate melting of the ice-particle cloud. Data from tests conducted at test-section speeds of $\mathrm{V}_{\infty} \sim 85 \mathrm{~m} / \mathrm{s}$ and a total pressure of $\mathrm{P}_{0} \sim 93 \mathrm{kPa}$ are presented in this paper as they represent a complete dataset from this test entry. Both the velocity and pressure were measured at the centerline of the tunnel just prior to the cloud on condition for nominally $30 \mathrm{sec}$ and averaged. Slight variations in the airspeed of $\pm 0.4 \mathrm{~m} / \mathrm{s}$ (standard deviation) were observed during a given test with the mean values over the dataset varying $\pm 1 \mathrm{~m} / \mathrm{s}$ (standard deviation).

Sample results from a single mixed-phase test are shown in Figure 2 with the test conditions listed in the caption. The top graph of this figure shows the raw readings from the 3 elements of the SEA multiwire probe as a function of time. As the cloud comes on, the readings from the cylindrical elements $(0.5$ and $2.1 \mathrm{~mm}$ ) stabilize in $\sim 10 \mathrm{sec}$ with the half-pipe taking slightly longer at $\sim 20 \mathrm{sec}$; these transient times are a combination of the cloud ramp-up time and/or probe response time. The cloud remains on for about 3 min with the last 90 data points $(\sim 100 \mathrm{sec})$ averaged to represent the reading for that test. For the data shown in Figure 2, the resulting average values are $5.23 \pm 0.38,1.51 \pm 0.06$, and $0.80 \pm 0.03 \mathrm{~g} / \mathrm{m}^{3}$ for the $\mathrm{TWC}_{\mathrm{m}}, \mathrm{LWC}_{\mathrm{m}, 0.5}$, and $\mathrm{LWC}_{\mathrm{m}, 2}$, respectively, where the error bars are the standard deviation of the measurement during the 100 -sec period. The averaged values are superimposed as horizontal hatched lines on the top graphs of Figure 2. All cases compared in this study are analyzed in an identical way with the 90-point average values compared in the subsequent analysis. The measured values listed in subsequent data tables also include the standard deviation (shown as error bars ${ }^{1}$ ) of the measurements during the 100-sec sampling interval. For some limited cases, there were unexplained spikes or rapid transient behaviors which were not immediately understood. For those data points, the time period for the average values was shifted to exclude those transient portions. A carrot $\left({ }^{\wedge}\right)$ is included next to the data point number in the data tables below if the time period for the average values was shifted. In no circumstances did these data points appear to be unusable.

The bottom graph of Figure 2 shows the raw readings of the $\mathrm{SH}$ at the test section measured approximately $89 \mathrm{~mm}$ below the centerline of the tunnel which corresponds to $36 \mathrm{~mm}$ above the bottom wall. The RH values are calculated based on these SH measurements as well as the instantaneous local total temperature at this below-centerline location. SH measurements from this below-centerline location were typically higher by $0.04 \pm 0.04 \mathrm{~g}_{\mathrm{H} 2 \mathrm{O}} / \mathrm{kg}_{\text {dry air }}$ compared to the centerline location. Here the error bar represents the standard deviation of the SH variation for the $85 \mathrm{~m} / \mathrm{s}$ and $93 \mathrm{kPa}$ dataset. For data point 673 shown in Figure 2, the SH reading increased by roughly $0.5 \mathrm{~g}_{\mathrm{H} 2 \mathrm{O}} / \mathrm{kg}_{\text {dry air }}$ after approximately $60 \mathrm{sec}$ of spray time. Correspondingly, the relative humidity at the test section increased although it appears to increase at a slightly faster rate than the SH. This behavior is likely attributable to the different measurement response times for $\mathrm{SH}$ and temperature as well as the time it takes for conditions to stabilize from the cloud-off to cloud-on conditions.

\footnotetext{
${ }^{1}$ For individual measurements, the error bar represents the standard deviation of the measurements from the mean value of that measurement during the sampling period (typically $100 \mathrm{sec}$ or as noted). For data sets, the error bars represent the standard deviation of the mean calculated from all data points in that data set.
} 


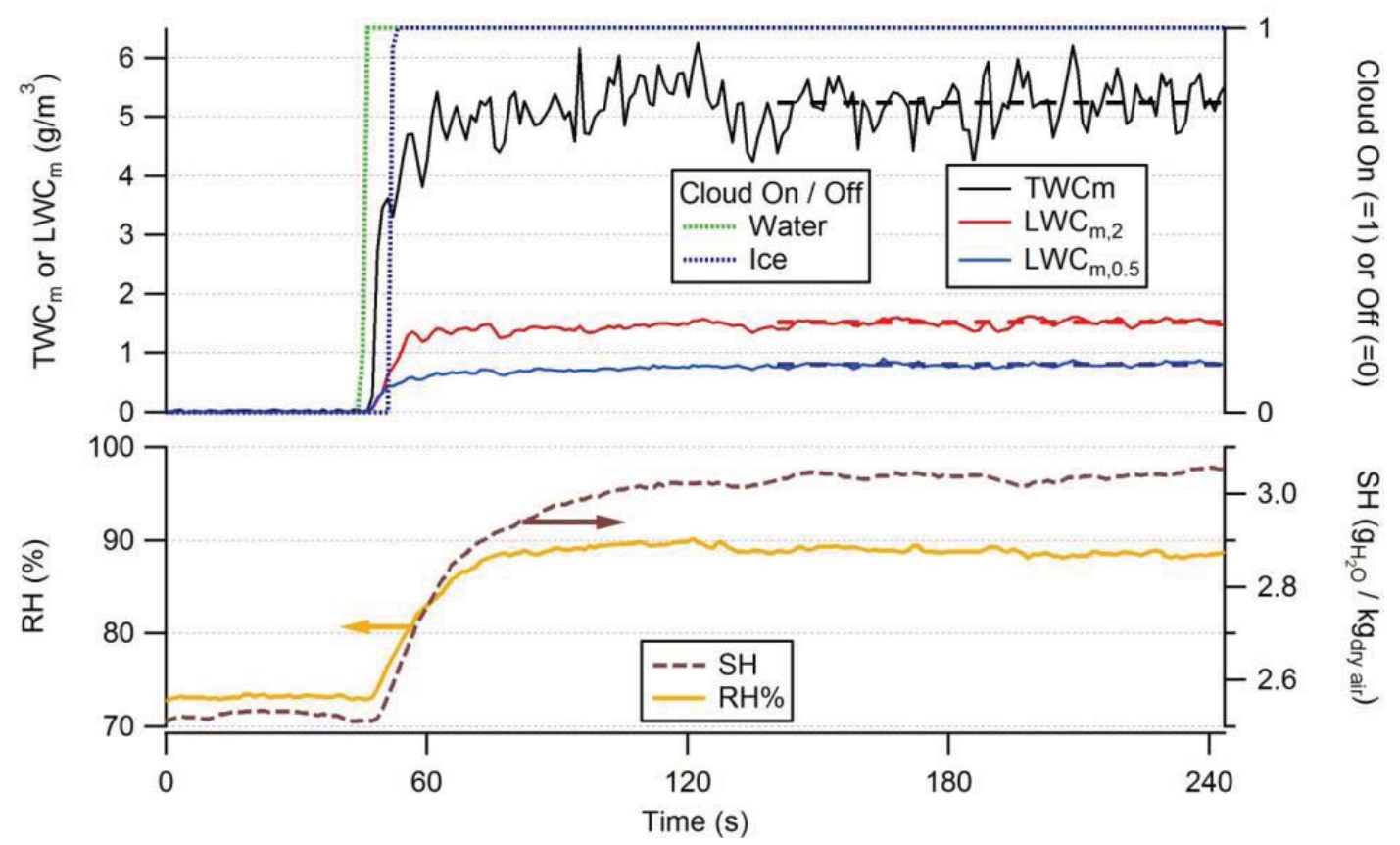

Figure 2.-Test data sample showing raw readings from the 3 elements of the SEA multi-wire probe (top graph) and test section humidity measurements (bottom graph). This data is from a mixedphase test (data point 673) where the $\mathrm{IWC}_{\mathrm{i}}=9.86 \mathrm{~g} / \mathrm{m}^{3}, \mathrm{LWC}_{\mathrm{i}}=0.87 \mathrm{~g} / \mathrm{m}^{3}$. During cloud-off conditions, the test section total velocity, pressure, and temperature were measured to be $86.2 \pm 0.4 \mathrm{~m} / \mathrm{s}, 93.08 \pm 0.04 \mathrm{kPa}$, and $-0.8 \pm 0.1^{\circ} \mathrm{C}$, respectively.

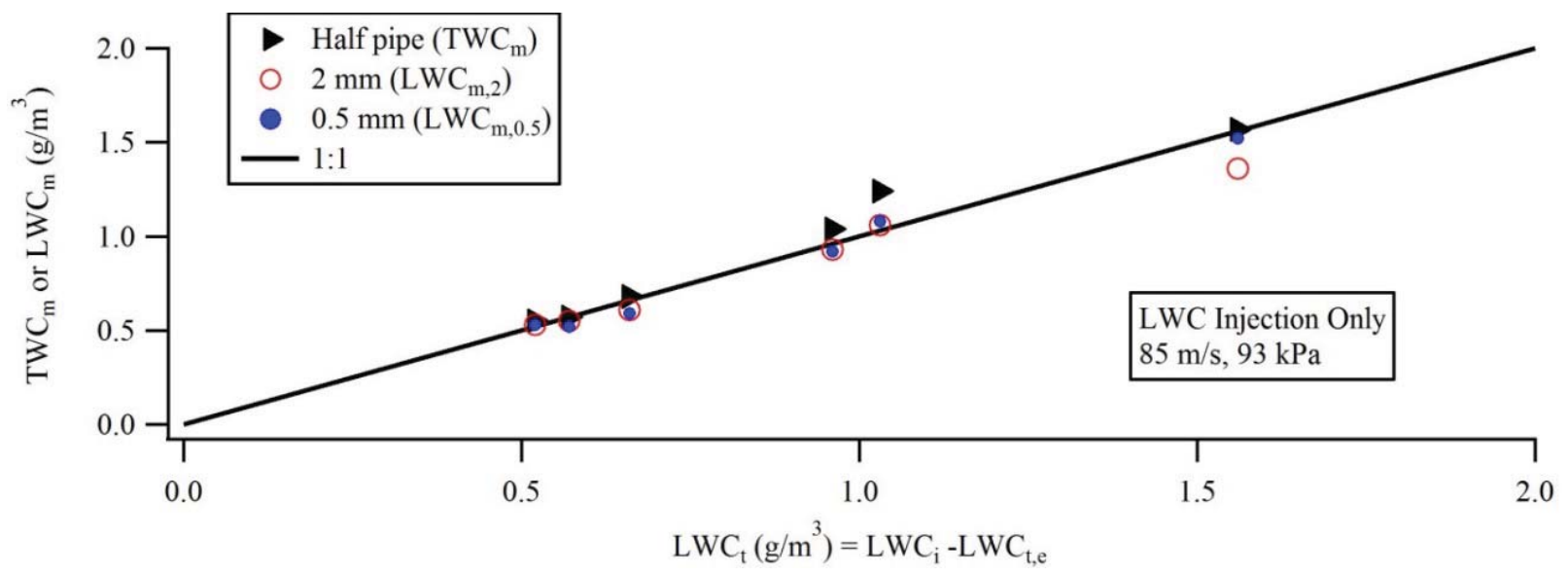

Figure 3.-Measured liquid water content as a function of liquid water content at the test section using a liquid-only spray at the following nominal conditions: TAT $=-1^{\circ} \mathrm{C}, \mathrm{V}=85 \mathrm{~m} / \mathrm{s}$, and $\mathrm{P}=93 \mathrm{kPa}$. The $\mathrm{LWC}_{\mathrm{t}}$ comes from subtracting the amount of mass evaporated from the injected values, as shown in Equation (1).

\subsubsection{LWC-Only Results}

Results from LWC-only tests are shown in Figure 3 with the raw data from the measurements shown in Table 1. In this figure, the liquid water content at the test section, $\mathrm{LWC}_{\mathrm{t}}$, is compared to measurements from all three elements of the hot-wire probe. In the figure, a reference line is shown where $\mathrm{LWC}_{\mathrm{t}}=\mathrm{LWC}_{\mathrm{m}}$ allowing a quick comparison of the measured versus test-section values. Overall, the $\mathrm{LWC}_{\mathrm{m}}$ values agree well with $\mathrm{LWC}_{\mathrm{t}}$. 
TABLE 1.-DATA FROM LIQUID-WATER ONLY SPRAYS

[The test section velocity was nominally $85 \mathrm{~m} / \mathrm{s}$ and the ambient pressure was $93 \mathrm{kPa}$ and the total air temperature was $-1{ }^{\circ} \mathrm{C}$. A carrot $\left({ }^{\wedge}\right)$ is included next to the data point number when the time period for the average values was adjusted from the last 100-sec.]

\begin{tabular}{|c|c|c|c|c|c|c|c|c|}
\hline $\begin{array}{c}\text { Data } \\
\text { Point }\end{array}$ & Nozzles & $\begin{array}{c}\mathrm{RH}_{0} \\
\text { (cloud off) }\end{array}$ & $\mathrm{LWC}_{\mathrm{i}}$ & $\mathrm{LWC}_{\mathrm{t}, \mathrm{e}}$ & $\mathrm{LWC}_{\mathrm{t}}$ & $\begin{array}{c}\mathrm{TWC}_{\mathrm{m}} \\
\text { (half-pipe) }\end{array}$ & $\begin{array}{c}\mathrm{LWC}_{\mathrm{m}, 2} \\
(2 \mathrm{~mm})\end{array}$ & $\begin{array}{c}\mathrm{LWC}_{\mathrm{m}, 0.5} \\
(0.5 \mathrm{~mm})\end{array}$ \\
\hline 620 & 2 & 24.7 & 0.88 & 0.36 & 0.52 & $0.55 \pm .08$ & $0.53 \pm .01$ & $0.53 \pm .01$ \\
\hline 594 & 2 & 22.1 & 1.69 & 0.66 & 1.03 & $1.24 \pm .09$ & $1.06 \pm .01$ & $1.08 \pm .02$ \\
\hline 598 & 4 & 20.0 & 1.77 & 0.81 & 0.96 & $1.04 \pm .08$ & $0.93 \pm .02$ & $0.92 \pm .03$ \\
\hline $641^{\wedge}$ & 4 & 25.3 & 2.63 & 1.07 & 1.56 & $1.57 \pm .09$ & $1.36 \pm .02$ & $1.52 \pm .03$ \\
\hline 657 & 2 & 37.5 & 0.88 & 0.31 & 0.57 & $0.57 \pm .04$ & $0.55 \pm .01$ & $0.52 \pm .01$ \\
\hline 668 & 2 & 72.8 & 0.88 & 0.22 & 0.66 & $0.68 \pm .04$ & $0.61 \pm .02$ & $0.59 \pm .02$ \\
\hline
\end{tabular}

Generally, the $\mathrm{TWC}_{\mathrm{m}}$ (i.e., half-pipe) values are greater than either the $\mathrm{LWC}_{\mathrm{m}, 0.5}$ or $\mathrm{LWC}_{\mathrm{m}, 2}$ values. For the cases where $\mathrm{LWC}_{\mathrm{t}}$ is approximately $1 \mathrm{~g} / \mathrm{m}^{3}$ and less, both $\mathrm{LWC}_{\mathrm{m}, 0.5}$ and $\mathrm{LWC}_{\mathrm{m}, 2}$ produce very similar readings and were within 5 percent of $\mathrm{LWC}_{\mathrm{t}}$. However, there was one case (data point 594) where $\mathrm{TWC}_{\mathrm{m}}$ was approximately 20 percent greater than $\mathrm{LWC}_{\mathrm{t}}$. Further examination of data point 594 did not offer any apparent anomalies.

For the larger test-section $\mathrm{LWC}_{\mathrm{t}}$ of $1.5 \mathrm{~g} / \mathrm{m}^{3}$ (data point 641 in Table 1), the $\mathrm{LWC}_{\mathrm{m}, 2}$ is about 13 percent less than $\mathrm{TWC}_{\mathrm{m}}$ but $\mathrm{LWC}_{\mathrm{m}, 0.5}$ is within a few percent of $\mathrm{LWC}_{\mathrm{t}}$. Such differences in response from the $0.5-\mathrm{mm}$ and $2.1-\mathrm{mm}$ elements have previously been attributed to drop size effects (e.g., see Figure 5 in Ref. 9). In the present tests, the liquid water spray is set at conditions which produced an MVD of $\sim 40 \mu \mathrm{m}$ at the nozzle outlet plane based on a sea-level calibration of a single nozzle. However, the actual MVD at the test section is likely larger than $40 \mu \mathrm{m}$ and, in fact, may vary from test to test due to the varying degree of evaporation that is occurring in these tests. Data point 641 did have a small spike (i.e., rapid increase then decrease) near the end of the sampling period which was not included in the analysis. Otherwise, data point 641 did not appear anomalous. Repeating this data point is warranted as well as comparing to spray MVD results before any further conclusions can be drawn.

Examination of the data (points 620,657, and 668) in Table 1 shows that as the RH of the test section increases under cloud-off conditions, the evaporated water mass decreases at the test section for the same injected $\mathrm{LWC}_{\mathrm{i}}$. This results in an increase in $\mathrm{LWC}_{\mathrm{t}}$ which is detected by all three elements of the probe with most of the readings being within 5 percent of $\mathrm{LWC}_{\mathrm{t}}$ with the remaining point being within $\sim 10$ percent of $\mathrm{LWC}_{\mathrm{t}}$ (7.6 percent for $\mathrm{LWC}_{\mathrm{m}, 2}$ and 10.6 percent for $\mathrm{LWC}_{\mathrm{m}, 0.5}$ in data point 668).

\subsubsection{IWC-Only Results}

Results from IWC-only tests are shown in Figure 4 and Figure 5. In Figure 4, the ice water content at the test section, $\mathrm{IWC}_{\mathrm{t}}$, is compared to measurements from the half pipe, $\mathrm{IWC}_{\mathrm{m}}$. In this figure, a reference line (solid black) is shown where $\mathrm{IWC}_{\mathrm{t}}=\mathrm{IWC}_{\mathrm{m}}$. The measurements are roughly half of the calculated testsection $\mathrm{IWC}_{\mathrm{t}}$, with a linear curve fit of the data (hatched line in Figure 4) yielding a factor of 48.5 percent measured versus test section. This results is consistent with previously published results (Ref. 13) although those results are at a different velocity and suggest that the measurements effectiveness varies with airspeed. Figure 5 shows the measured false response, $\mathrm{LWC}_{\mathrm{FR}}$, for both of the cylindrical elements, $\mathrm{LWC}_{\mathrm{m}, 0.5}$ and $\mathrm{LWC}_{\mathrm{m}, 2}$, along with a linear curve fit of the data. Again, a false response is the signal produced by ice crystals on the cylindrical elements which are intended for liquid water measurements. The curve fits suggest a false response of approximately 4 to 5 percent of the injected ice-particle clouds generated in this study. However, the dataset is sparse with some scatter. Furthermore, the correct relationship between the $\mathrm{LWC}_{\mathrm{FR}}$ and $\mathrm{IWC}_{\mathrm{t}}$ may not be linear and would require more data to better define.

The data used for the calculations of the $\mathrm{IWC}_{\mathrm{t}}$ in Figure 4 and Figure 5 including the measured evaporation are shown in Table 2. Examination of the data shows that the amount of evaporated mass increases with injected $\mathrm{IWC}_{\mathrm{i}}$ when maintaining the same test-section $\mathrm{RH}$ under cloud-off conditions (data points 576, 582, and 588). Also, the evaporated mass decreases with increasing test section $\mathrm{RH}$ (data points 576 and 569) as expected and is similar to the LWC-only tests. 


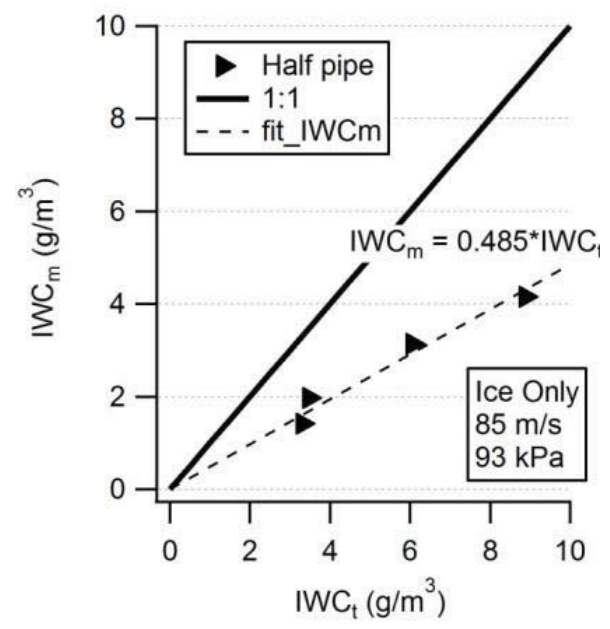

Figure 4.-Measured IWC from the half-pipe versus test section $\mathrm{IWC}_{\mathrm{t}}$ at the following nominal conditions: $\mathrm{TAT}=-1^{\circ} \mathrm{C}, \mathrm{V}=85 \mathrm{~m} / \mathrm{s}$, and $\mathrm{P}=93 \mathrm{kPa}$.

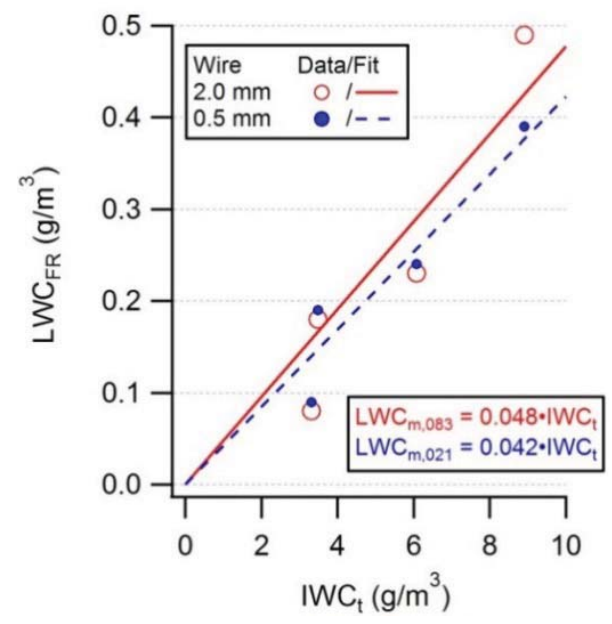

Figure 5.-False response of the LWC elements versus IWC . The IWC $\mathrm{IW}_{t}$ comes from subtracting the sublimated mass from the injected values.

TABLE 2.-DATA FROM ICE-ONLY SPRAYS

[The test section velocity was nominally $85 \mathrm{~m} / \mathrm{s}$ and the ambient pressure was $93 \mathrm{kPa}$ and the total air temperature was $-1{ }^{\circ} \mathrm{C}$. A carrot $(\wedge)$ is included next to the data point number when the time period for the average values was adjusted from the last 100 -sec.]

\begin{tabular}{|c|c|c|c|c|c|c|c|}
\hline Data point & $\begin{array}{c}\mathrm{RH} \\
\text { (cloud off), } \\
\%\end{array}$ & $\mathrm{IWC}_{\mathrm{i}}$ & $\mathrm{IWC}_{\mathrm{t}, \mathrm{s}}$ & $\mathrm{IWC}_{\mathrm{t}}$ & $\begin{array}{c}\mathrm{TWC}_{\mathrm{m},} \\
\mathrm{IWC}_{\mathrm{m}}\end{array}$ & $\mathrm{LWC}_{\mathrm{m}, 2}$ & $\mathrm{LWC}_{\mathrm{m}, 0.5}$ \\
\hline 569 & 30.8 & 4.02 & 0.53 & 3.49 & $1.97 \pm .38$ & $0.18 \pm .01$ & $0.19 \pm .01$ \\
\hline $576^{\wedge}$ & 22.6 & 3.93 & 0.61 & 3.32 & $1.42 \pm .22$ & $0.08 \pm .01$ & $0.09 \pm .01$ \\
\hline 582 & 22.7 & 6.84 & 0.77 & 6.07 & $3.14 \pm .29$ & $0.23 \pm .02$ & $0.24 \pm .02$ \\
\hline 588 & 22.1 & 9.78 & 0.88 & 8.90 & $4.15 \pm .41$ & $0.49 \pm .05$ & $0.39 \pm .02$ \\
\hline
\end{tabular}

\subsubsection{Mixed-Phase Results}

For the mixed-phase tests, both $\mathrm{IWC}_{\mathrm{i}}$ and supplemental $\mathrm{LWC}_{\mathrm{i}}$ were injected into the test section. Again, the TAT was maintained at a target temperature of $-1{ }^{\circ} \mathrm{C}$ to prevent the $\mathrm{IWC}_{\mathrm{i}}$ from melting. Evaporation was again calculated by measuring the humidity change in the test section with the cloud off and on. In this way, we set out to achieve a "known" mixed-phase cloud and examine its results on the SEA multi-wire probe. For the half-pipe, there is a contribution from both the IWC and LWC. For the cylindrical elements, the measured LWC in mixed phase would be that of the supplemental LWC plus a contribution due to a false response from ice particles.

In this paper, we put forth and test the following hypothesis:

The half-pipe TWC measurement in mixed-phase is a superposition of the individual IWC and $L W C$ components. The individual LWC and IWC measurements can be corrected to the actual values using calibrations from separate LWC and IWC clouds. In mixed-phase, the LWC measurements should use the maximum measurement from either the 0.5 or 2.1-mm diameter element and subtract the false response due to the ice particles.

The hypothesis is tested by solving for LWCt* and $\mathrm{IWCt}^{*}$ (and hence $\mathrm{TWCt}^{*}$ ) as shown in Equation (10) and (11) using measurements made in mixed phase. Here, the asterisk (*) denotes values at the test section calculated using the mixed-phase hypothesis. These calculations require solving for the false response contribution of ice particles on the liquid-water elements, LWCFR, as shown in Equation (12). For this analysis, we use the average of the curve fit values $\left(0.045 \cdot \mathrm{IWCt}^{*}\right)$ 
from Figure 5 to calculate LWCFR. However, the corrections for the specific element shown in Figure 5 can be used. There are three unknowns in Equations (10) to (12), $\mathrm{LWC}_{\mathrm{t}}^{*}, \mathrm{IWC}_{\mathrm{t}}^{*}$, and $\mathrm{LWC}_{\mathrm{FR}}$, which are solved by iteration.

$$
\begin{gathered}
\mathrm{LWC}_{\mathrm{t}}^{*}=\max \left(\mathrm{LWC}_{\mathrm{m}, 083}, \mathrm{LWC}_{\mathrm{m}, 021}\right)-\mathrm{LWC}_{\mathrm{FR}} \\
\mathrm{IWC}_{\mathrm{t}}^{*}=\frac{\mathrm{TWC}_{\mathrm{m}}-\mathrm{LWC}_{\mathrm{t}}^{*}}{0.485} \\
\mathrm{LWC}_{\mathrm{FR}}=0.045 \cdot \mathrm{IWC}_{\mathrm{t}}^{*}
\end{gathered}
$$

To validate the hypothesis, we compare the calculated total water content injected, $\mathrm{TWC}_{\mathrm{i}}{ }^{*}$, to the actual injected total water injected, $\mathrm{TWC}_{\mathrm{i}}$. The $\mathrm{TWC}_{\mathrm{i}}{ }^{*}$ is calculated by adding the amount of humidity increase at the test section due to evaporation and sublimation with the cloud on compared to the cloud off - see Equation (7). If the $\mathrm{TWC}_{\mathrm{i}}{ }^{*}$ and $\mathrm{TWC}_{\mathrm{i}}$ are comparable then the proposed hypothesis of superposition is supported for the conditions tested. Note that the method only can validate the $\mathrm{TWC}_{\mathrm{t}}{ }^{*}$ values and cannot individually validate the $\mathrm{IWC}_{\mathrm{t}}{ }^{*}$ and $\mathrm{LWC}_{\mathrm{t}}{ }^{*}$ values because the individual contributions of evaporation and sublimation cannot be separated in the mixed-phase cloud.

Figure 6 compares $\mathrm{TWC}_{\mathrm{i}}{ }^{*}$ and $\mathrm{TWC}_{\mathrm{i}}$ to examine the hypothesis put forth to interpret the SEA multiwire probe in mixed-phase conditions. For reference, a 1:1 line is included in the figure to facilitate comparison between the two values. The data used to calculate the $\mathrm{TWC}_{\mathrm{i}}{ }^{*}$ is shown in Table 3 . For total water contents of $8.5 \mathrm{~g} / \mathrm{m}^{3}$ and less (data points 625,646 , and 636), the calculated injected $\mathrm{TWC}_{\mathrm{i}}{ }^{*}$ compares to within 6 percent of the actual injected $\mathrm{TWC}_{\mathrm{i}}$. In two cases (646 and 636), the comparison is approximately 1 percent or less. For cases where $\mathrm{TWC}_{\mathrm{i}}$ is $10.7 \mathrm{~g} / \mathrm{m}^{3}$ and greater $(673,631$, and 652$)$, the $\mathrm{TWC}_{\mathrm{i}}$ * is less than the actual $\mathrm{TWC}_{\mathrm{i}}$ by 10 to 12 percent. This suggests that the hypothesis may be supported for total water contents below approximately $7.5 \mathrm{~g} / \mathrm{m}^{3}$ (e.g., $\mathrm{TWC}_{\mathrm{t}}{ }^{*}$ for data point 636 ) but seems to break down as the $\mathrm{TWC}_{\mathrm{t}}$ becomes larger. However, more data at the higher water loadings should be generated before reaching firm conclusions. Furthermore, these results are for velocities of $85 \mathrm{~m} / \mathrm{s}, 93 \mathrm{kPa}$, and the "small" particle size and the calibration curves, such as the factor $0.485 \mathrm{in}$ Equation (11), may only be valid at those conditions. More data needs to be generated at other test conditions to confirm the validity of the hypothesis at those conditions.

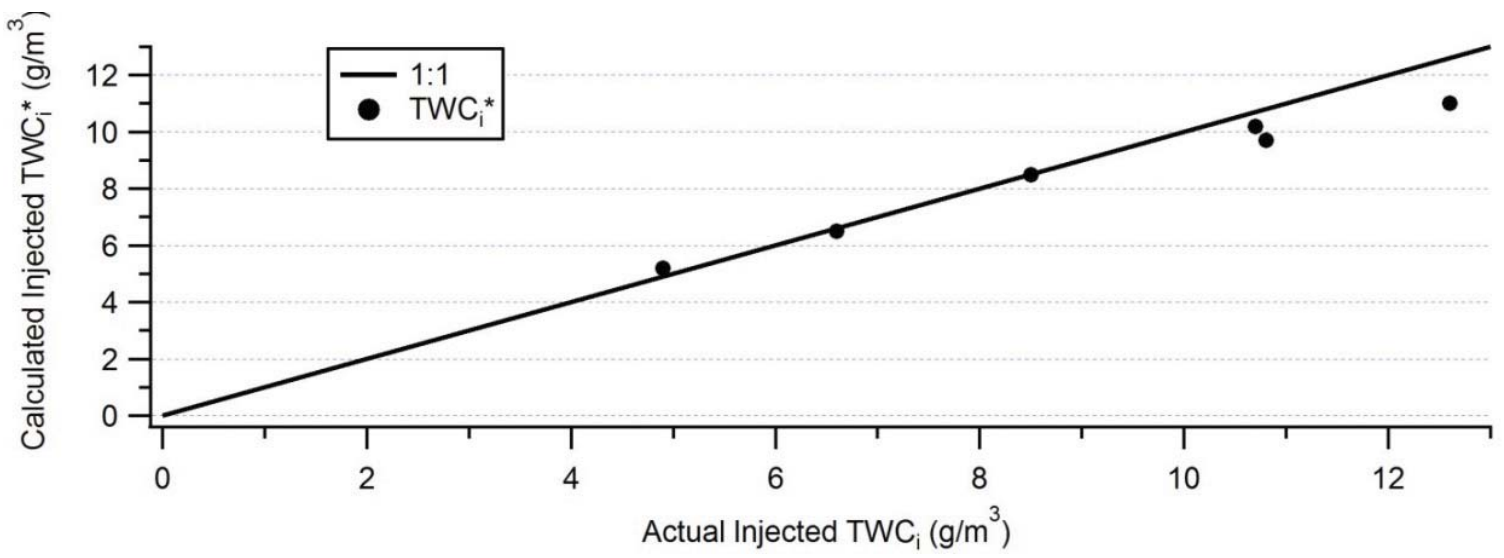

Figure 6.-Comparison of injected TWC calculated from measurements made in mixed phase to actual injected TWC for tests conducted at nominally $85 \mathrm{~m} / \mathrm{s}$ and $93 \mathrm{kPa}$. This data tests the hypothesis that mixed-phase measurements superimpose on a non-interfering basis. 
TABLE 3.-DATA FROM MIXED-PHASE TESTS WITH ICE AND SUPPLEMENTAL LIQUID WATER

[The test section velocity was nominally $85 \mathrm{~m} / \mathrm{s}$, the ambient pressure was $93 \mathrm{kPa}$, and the total air temperature was $-1{ }^{\circ} \mathrm{C}$.

Due to the below freezing temperature, the ice particles presumably would not melt and all contribution of LWC would be due to the supplemental water. A carrot $\left(^{\wedge}\right)$ is included next to the data point number when the time period for the average values was adjusted from the last $100-\mathrm{sec}$.]

\begin{tabular}{|c|c|c|c|c|c|c|c|c|c|c|c|c|}
\hline \multirow[b]{2}{*}{$\begin{array}{l}\text { Data } \\
\text { Point }\end{array}$} & \multirow[b]{2}{*}{$\begin{array}{c}\mathrm{RH}, \\
\%\end{array}$} & \multicolumn{3}{|c|}{ Multi-wire measurements } & \multicolumn{3}{|c|}{ From algorithm } & \multirow{2}{*}{$\begin{array}{c}\begin{array}{c}\text { Measured } \\
\text { evap+sub }\end{array} \\
\mathrm{TWC}_{\mathrm{s}+\mathrm{e}}\end{array}$} & \multirow{2}{*}{$\begin{array}{c}\text { Calculated } \\
\text { injected }\end{array}$} & \multicolumn{3}{|c|}{ Injected } \\
\hline & & $\mathrm{TWC}_{\mathrm{m}}$ & $\mathrm{LWC}_{\mathrm{m}, 2}$ & $\mathrm{LWC}_{\mathrm{m}, 0.5}$ & $\mathrm{LWC}_{\mathrm{t}^{*}}$ & $\mathrm{IWC}_{\mathrm{t}^{*}}$ & $\mathrm{TWC}_{\mathrm{t}^{*}}$ & & & $\mathrm{TWC}_{\mathrm{i}}$ & $\mathrm{LWC}_{\mathrm{i}}$ & $\mathrm{IWC}_{\mathrm{i}}$ \\
\hline 625 & 25.5 & $2.28 \pm 0.23$ & $0.47 \pm 0.01$ & $0.48 \pm 0.01$ & 0.30 & 4.08 & 4.38 & 0.80 & 5.18 & 4.90 & 0.88 & 4.02 \\
\hline $646^{\wedge}$ & 25.2 & $3.20 \pm 0.20$ & $1.50 \pm 0.03$ & $1.39 \pm 0.03$ & 1.33 & 3.85 & 5.18 & 1.34 & 6.53 & 6.61 & 2.63 & 3.98 \\
\hline 636 & 25.9 & $4.25 \pm 0.24$ & $1.51 \pm 0.04$ & $1.06 \pm 0.02$ & 1.23 & 6.23 & 7.46 & 1.02 & 8.48 & 8.52 & 1.71 & 6.81 \\
\hline 673 & 73.2 & $5.23 \pm 0.38$ & $1.51 \pm 0.06$ & $0.80 \pm 0.03$ & 1.13 & 8.45 & 9.58 & 0.59 & 10.17 & 10.73 & 0.87 & 9.86 \\
\hline 631 & 25.5 & $4.59 \pm 0.34$ & $1.12 \pm 0.04$ & $0.62 \pm 0.02$ & 0.77 & 7.89 & 8.65 & 1.00 & 9.65 & 10.78 & 0.87 & 9.91 \\
\hline 652 & 26.9 & $5.62 \pm 0.39$ & $2.07 \pm 0.13$ & $1.12 \pm 0.05$ & 1.71 & 8.07 & 9.78 & 1.27 & 11.05 & 12.56 & 2.63 & 9.93 \\
\hline
\end{tabular}
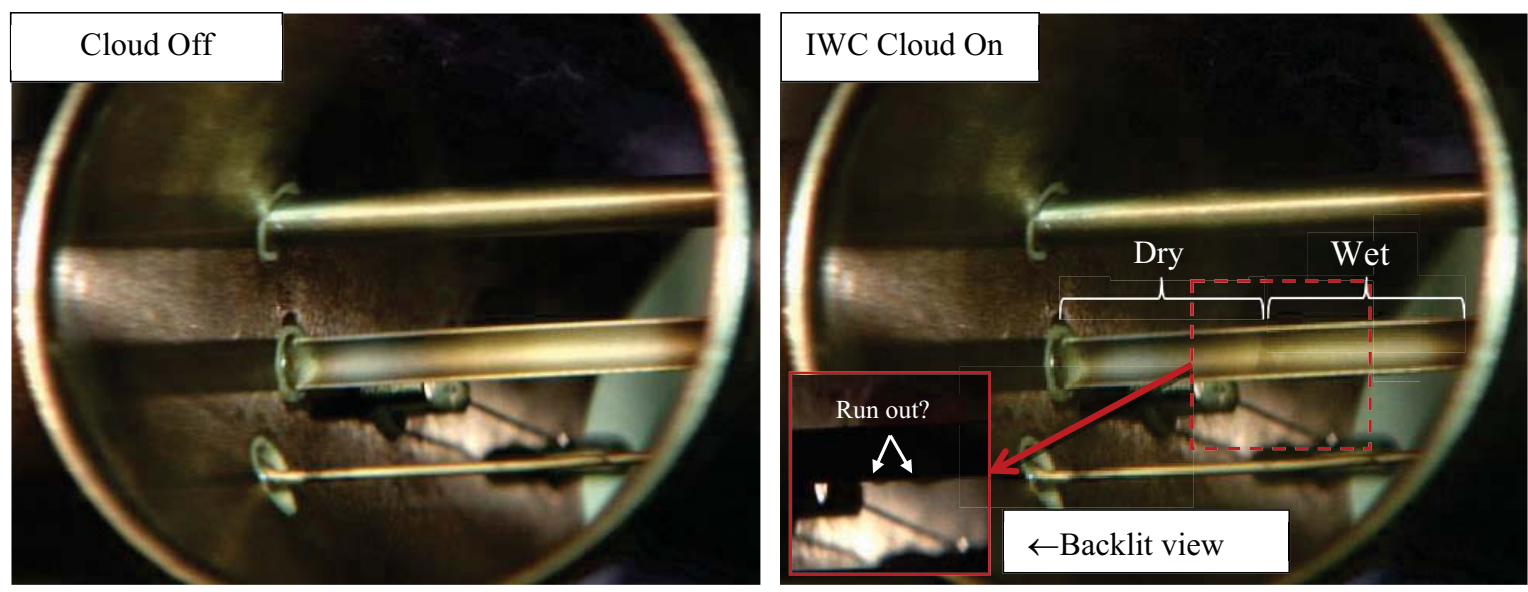

Figure 7.-Images of the front face of the SEA multi-wire probe taken during the March 2012 test campaign. The images are from data point 582 which had a test section IWC $\mathrm{IW}_{\mathrm{t}} \sim 6 \mathrm{~g} / \mathrm{m}^{3}$. With the ice cloud on, the half-pipe of the SEA multi-wire probe has what appear to be dry and wetted regions. The inset view shows an image of the probe during the same data point but backlit producing a shadow view of the elements.

\subsubsection{Multi-Wire Probe Imaging}

As part of the March 2012 test campaign, a high-definition video camera was positioned to image the elements of the SEA multi-wire probe with the cloud on. This was done to see if a portion of the incoming water flux was either bouncing or splashing from the elements prior to evaporation. In all of the tests with injected $\mathrm{IWC}_{\mathrm{i}}$, a portion of the half-pipe appeared to be wetted and a portion appeared to be running dry. Figure 7 shows two still images extracted from the videos for data point 582: one image was taken with the cloud off, the other with the cloud on. In this case, the test section $\mathrm{IWC}_{\mathrm{t}}$ was calculated to be $\sim 6 \mathrm{~g} / \mathrm{m}^{3}$ and the element was wetted from approximately the mid-point to the rightmost visible portion of the element. A cursory examination of other videos suggests that the wetted region increases with increasing $\mathrm{IWC}_{\mathrm{t}}$. Videos taken during LWC-only data points did not have visible dry and wetted regions. Finally, the probe was back illuminated during portions of the video recording to see if there was any evidence of splashing. The inset image in Figure 7 shows a portion of a frame from data point 582 that captured an event where beads of water appear to be run out of the half-pipe. A more detailed analysis is currently underway as well as discussions with the manufacturer of the probe to help interpret these observations from the video data. 


\subsection{Cloud Uniformity}

The uniformity of LWC and IWC clouds was gauged non-intrusively using a laser sheet positioned in the test section normal to the flow direction (Figure 8). As water and ice particles pass through the laser sheet, they scatter light, which is then measured by a camera. The laser sheet was created using a fibercoupled diode laser $(1.5 \mathrm{~W}, 532 \mathrm{~nm})$ and spanned the entire height of the test section but only half the width limited to the existing window size. The laser sheet was positioned approximately $70 \mathrm{~mm}$ ahead of the SEA multi-wire probe. A scientific-grade slow-scan imaging camera was positioned downstream and outside of the test section looking back at the laser sheet at an off-normal viewing angle through the large side window in the Cascade rig. In this position, the camera would capture forward-scattered light from the particles passing through the laser sheet. The camera took a sequence of images (approximately 50 images over a period of $\sim 25 \mathrm{sec}$ ) beginning roughly as the cloud was turned on. Each image had an exposure of $0.5 \mathrm{sec}$ and had a 14-bit dynamic range. During the imaging, the light in the test cell was minimized because any light source could be detected as a false signal by the imager. Furthermore, reflections of the laser source itself from surfaces in the test cell could mask any signal from particlescattered light.

The right-hand side of Figure 8 shows a sample image taken during testing with an ice-only cloud with a TAT $<0{ }^{\circ} \mathrm{C}$. The yellow line in this figure defines a region of interest (ROI) used for the subsequent analysis. This ROI was defined to avoid areas of laser-light reflection (seen as bright spots near the periphery of the ROI) which masks the forward-scattered light from the particles. The average intensity in the ROI was computed for each image of the sequence. Results from the LWC-only data points are presented in Figure 9. In the left graph of this figure, the average intensity of each image is shown as a function of time. The start of the imaging sequence was manually initiated to coincide with the beginning of the spray. However, only one data point (641) shows an increasing trend near the beginning of the sample period while the other data points appear to be about constant suggesting that the spray was initiated prior to the beginning of the imaging sequence. On the right graph shown in Figure 9, the intensity averaged over all the image frames (or as denoted in the figure) is plotted against the liquid water content calculated to be at the test section, $\mathrm{LWC}_{\mathrm{t}}$ (injected $\mathrm{LWC}_{\mathrm{i}}$ minus evaporated $\mathrm{LWC}_{\mathrm{e}}$ ). The graph shows that the average intensity appears to increase proportionally with increasing $\mathrm{LWC}_{\mathrm{t}}$. Figure 10 shows results from a similar analysis performed with an IWC-only cloud. A larger average intensity is

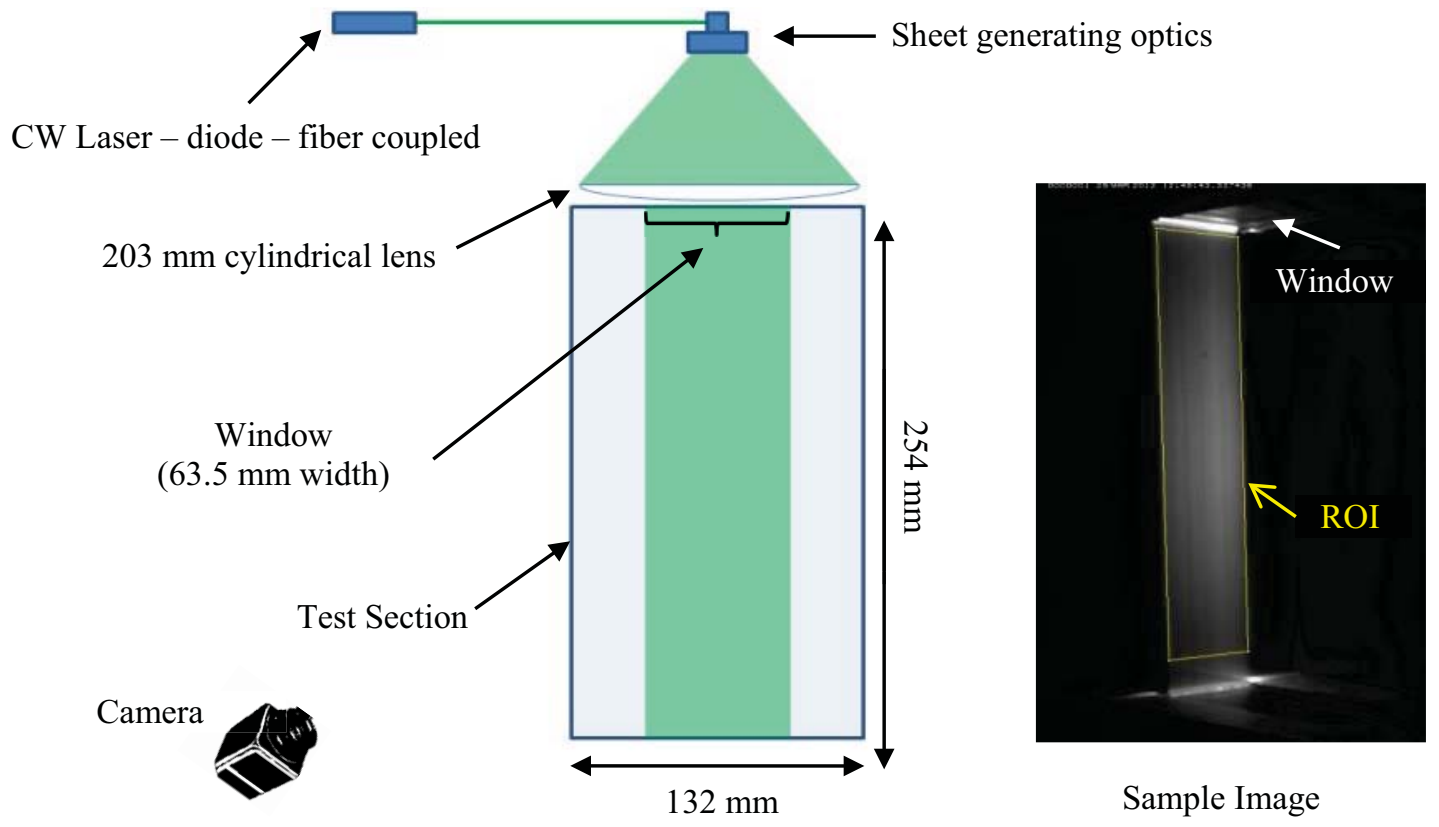

Figure 8.-Laser sheet cloud uniformity setup and sample image. 

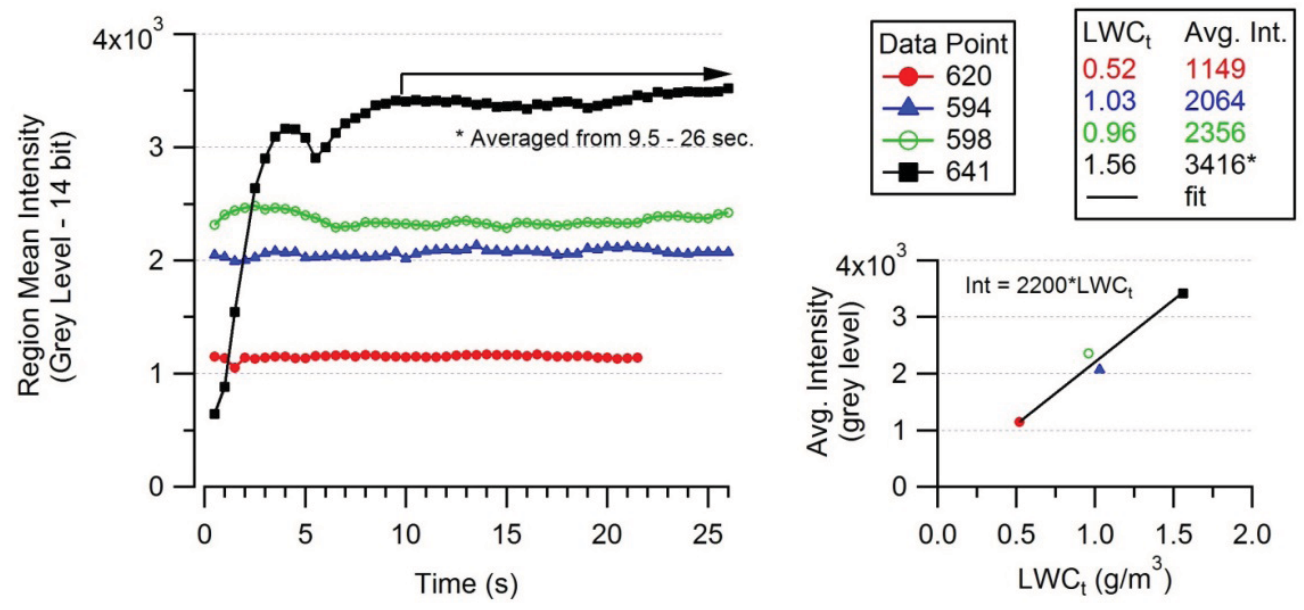

Figure 9.-Mean intensity level for the region of interest shown in Figure 8 with LWC-only sprays at $85 \mathrm{~m} / \mathrm{s}$ and $93 \mathrm{kPa}$ total pressure. The left graph shows the mean intensity for each image as a function of time. The right graph shows a time-average intensity across all image (or as specified) plotted versus LWC $_{t}$.
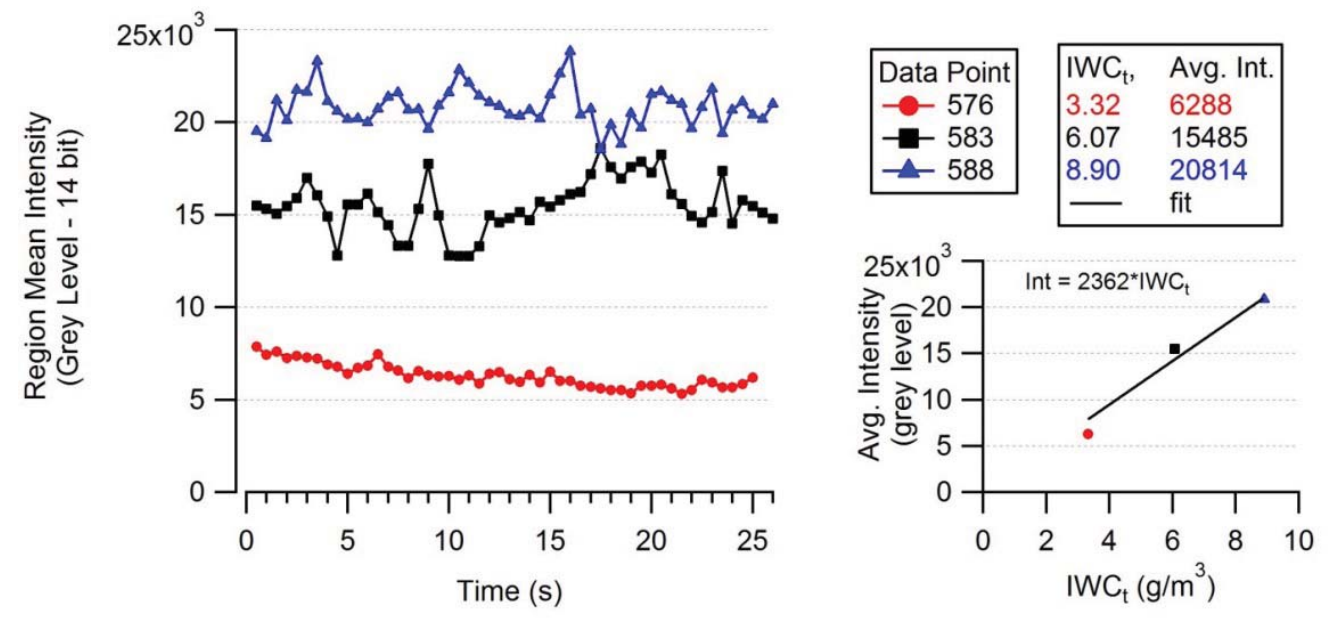

Figure 10.-Mean intensity level for the region of interest shown in Figure 8 with IWC-only sprays at $85 \mathrm{~m} / \mathrm{s}$ and $93 \mathrm{kPa}$ total pressure. The left graph shows the mean intensity for each image as a function of time. The right graph shows the time-averaged intensity plotted versus IWC .

measured with the IWC clouds presumably owing to the increased concentration. Comparison of a linear curve fit of the average intensity versus $\mathrm{LWC}_{\mathrm{t}}$ shows a slope of $2200 \pm 364$ counts per $\mathrm{g} / \mathrm{m}^{3}$. Here the error band is 95 percent confidence interval. The slope of the average intensity versus $\mathrm{IWC}_{\mathrm{t}}$ is $2362 \pm 155$ counts per $\mathrm{g} / \mathrm{m}^{3}$ and is essentially identical considering the confidence intervals of the data. This result suggests that the measured intensity is a good first-order measurement of concentration, independent of the water phase.

Figure 11 shows images generated by averaging the entire image sequence and applying a color lookup table which maps an average-intensity value to a color. The pixel intensities range from 2000 to over 30,000 counts. The images were transformed to map the pixel intensities to the 2D plane of the laser sheet. As a result, the image corresponding to data point 576 appears slightly warped as is evident by inspecting the upper portion of this image. The upper region of the remaining images was cropped and scaled to match the left-most image. Note that only the middle portion of the test section is mapped in this analysis - regions without information are shown in black. 


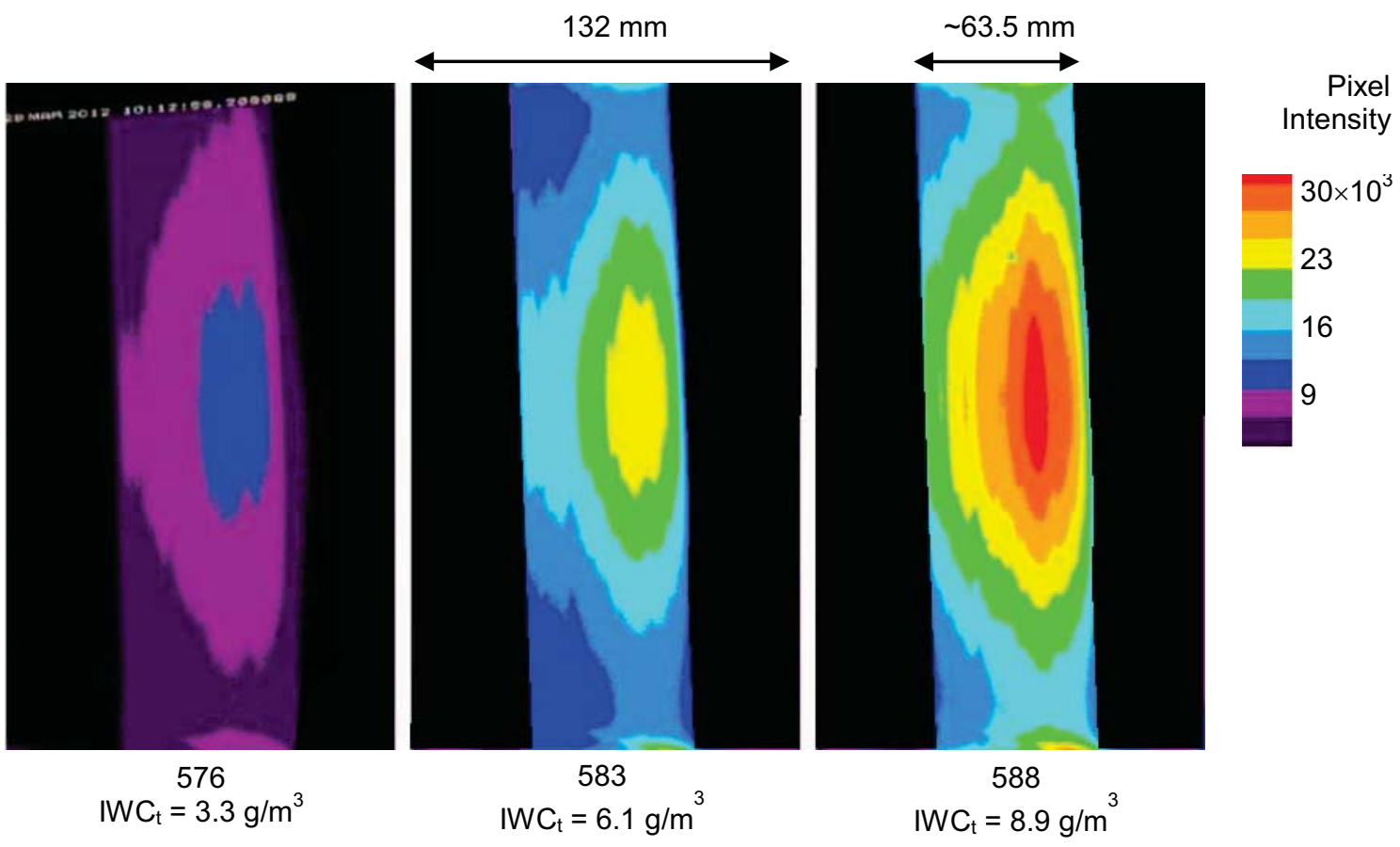

Figure 11.-Cloud uniformity estimates using laser sheet measurements averaged over the sampling period for 3 values of $\mathrm{IWC}_{\mathrm{t}}$ at the test section for the same flow condition (nominally $85 \mathrm{~m} / \mathrm{s}$ and $93 \mathrm{kPa}$ ).

Figure 11 shows 3 data points from the $85 \mathrm{~m} / \mathrm{s}$ and $93 \mathrm{kPa}$ data set with increasing $\mathrm{IWC}_{\mathrm{t}}$ from left to right. The intensity profiles show ellipse-like concentric regions with the highest counts near the center of the test section for each case. As the $\mathrm{IWC}_{\mathrm{t}}$ increases, greater intensities and steeper intensity gradients are observed in the test section. In previous work (Ref. 14), the intensity has been related to the local LWC or IWC through the use of a transfer-point measurement via an in-situ calibration (usually via a single-point probe measurement) to produce quantitative LWC or IWC information across the test section. In this work, we are examining the use of the average intensity and bulk (i.e., assumed uniformly mixed) $\mathrm{LWC}_{t}$ or $\mathrm{IWC}_{\mathrm{t}}$ as the transfer function. For example, one could use data from the curve fit from the data shown in Figure 10. However, such a transfer function needs also to consider the local flow velocity where increases in velocity also presumably increase the measured intensity counts as more particles traverse a given point in a given time interval. It is noted that this work is still preliminary and further analysis is ongoing. Ideally, future tests could map the entire test section which would require a laser sheet to span the entire cross-section. Ultimately, such data could be used to calculate local IWC and LWC values which then could be used in analyses like that performed in the previous section of the SEA multi-wire probe analysis

\subsection{Particle Size-Spectra and Velocity}

Due to the small test-section size of the Cascade rig in the NRC RATFac, flight-probe technology has not been easily adaptable to measure particle size spectra and velocity. As a result, NRC has been developing a custom Particle Imaging Velocimetry (PIV) system using a shadowgraph method (Ref. 7) for the purpose of measuring particle size and velocity. For the 2012 test entry, the PIV system was used to image particles in the center of the test section near where the leading edge of airfoil would be (see Figure 13 or refer back to Figure 1). This location is approximately $150 \mathrm{~mm}$ downstream of where the SEA multi-wire probe was located. For testing with the NRC PIV system, the test section was empty and the SEA multi-wire probe was retracted. 
Additionally, NASA is investigating the use of a high-speed camera coupled with a pulsed LED backlight to measure particle size and velocity. For this 2012 test entry, the high-speed system was used to take measurements near the ice-injection duct exit (Figure 14). Various positions near the ice injection outlet were measured - during the first day of tests it was observed that there were significantly fewer particles at the centerline of the ice-injection duct so the camera was repositioned to focus on regions within $\sim 10 \mathrm{~mm}$ of the inner periphery of the duct. Additionally, some measurements were made near the bellmouth entrance (see Figure 1 for the bellmouth location).

A quick comparison of both the PIV and high-speed camera system is shown in Table 4. Each measurement is essentially a point measurement in the cloud due to the small field of view (FOV). By making particle size measurements at two different downstream locations in the cloud, a desired objective was to quantify any changes in particle size and perhaps particle state, the latter would be accomplished by contrasting particle shape descriptors. Particle velocity measurements help quantify the flowfield and particle impact dynamics. The status of the NRC PIV and NASA high-speed imaging is presented below.

TABLE 4.-QUICK COMPARISON OF PARTICLE IMAGING SYSTEMS

\begin{tabular}{|l|c|c|c|}
\hline System & PIV & $\begin{array}{c}\text { High-speed camera / } \\
\text { LED }\end{array}$ & $\begin{array}{c}\text { High-speed camera / } \\
\text { LED }\end{array}$ \\
\hline Mode & N/A & Particle Counting & Velocity Measurement \\
\hline Field of view & 4.5 - by $4.5-\mathrm{mm}$ & $\begin{array}{c}9.07-\text { by } 5.67-\mathrm{mm} \\
(1280 \times 800 \text { pixels })\end{array}$ & $\begin{array}{c}9.07 \text { - by } 1.08-\mathrm{mm} \\
(1280 \times 152 \text { pixels })\end{array}$ \\
\hline Resolution & $1.3 \mu \mathrm{m} / \mathrm{pixel}$ & $7.08 \mu \mathrm{m} / \mathrm{pixel}$ & $7.08 \mu \mathrm{m} / \mathrm{pixel}$ \\
\hline Exposure time & $9 \mathrm{~ns}$ & 100 to $300 \mathrm{~ns}$ & 100 to $300 \mathrm{~ns}$ \\
\hline Sample rate & 2.5 to $5 \mathrm{fps}$ & $1000 \mathrm{fps}$ & $30,000 \mathrm{fps}$ \\
\hline
\end{tabular}

\subsection{NRC PIV}

The system used by NRC for particle imaging was a non-intrusive, high magnification shadowgraphy technique based on a LaVision PIV system. A diffused laser beam of uniform intensity was pulsed into a high resolution camera through a long distance microscope. The pulsed backlight illumination freezes the particles in a sample volume defined by the field of view and depth of field of the optics. In addition to particle sizing, this system can also be used for particle velocity and direction measurements.

One of the main advantages of this system is the short exposure time due to the laser pulse duration of 9 ns. This freezes the particles in the image thus minimizing the blur due to movement even at high test speeds of $200 \mathrm{~m} / \mathrm{s}$ and beyond. Typically, an image intensity is on the order of 3000 counts in clean flow and approximately 500 counts when a particle was imaged. The system also has high resolution which provides the ability to resolve a wide range of particle sizes, approximately 10 to $1500 \mu \mathrm{m}$ in diameter. This high resolution combined with the field of view requires large amounts of data to be transmitted from the camera to the data storage computer. The result is a relatively slow sample rate thereby requiring test times in the order of 10 to $20 \mathrm{~min}$ depending on particle concentration and distribution characteristics. The general specifications of this shadowgraphy system are given in Table 4 with a detailed description of its use for ice particle imaging and particle sizing provided elsewhere (Refs. 7 and15). For this work, the NRC shadowgraphy PIV system was oriented normal to the axis of the test section, with the focal plane and line of site coincident with the tunnel centerline as shown in Figure 13. Due to the low pressure and cold environment in the test chamber, the imaging hardware was installed in an enclosure which maintained the temperature above $0{ }^{\circ} \mathrm{C}$ and pressure above $70 \mathrm{kPa}$ for all test conditions. To eliminate the need for a similar enclosure for the laser and its power supplies, these items were installed outside of the chamber with the laser light entering the chamber through a window. This laser beam was then directed to the diffuser using mirrors. The PIV computer was located outside of the chamber and was used to control the system and store the images. Figure 12 is a cropped image, approximately $1 / 4$ of full size, and illustrates the type of particle imaging that was obtained and used for particle analysis. Post processing was conducted using LaVision $\mathrm{DaV}$ is 8.1 particle sizing/image analysis software with the results to be presented at a later date. 


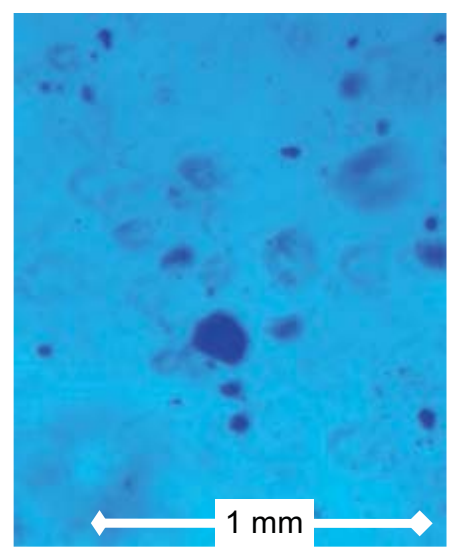

Figure 12.-Sample particle images from the NRC shadowgraphy PIV system.

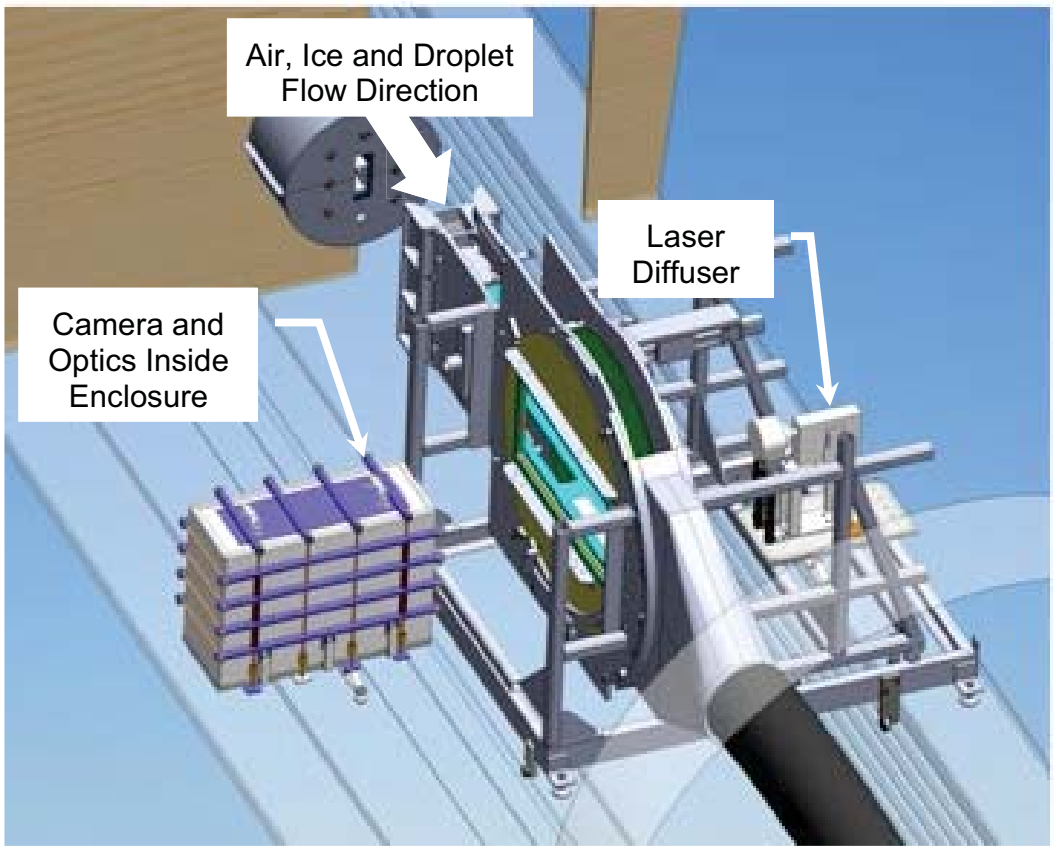

Figure 13.--Setup of NRC shadowgraphy PIV system used for particle imaging in the test section

\subsubsection{NASA Phantom Camera/LED System}

To measure both particle size distributions and velocity, NASA conducted some exploratory work using a high-speed camera coupled with a pulsed LED backlight system as seen in Figure 14. To avoid blurring of particles, it is essential to have an exposure which is shorter than the time required for a particle to move one (ideally) or just a few pixels. The camera's minimum exposure time is $1 \mu \mathrm{s}$. At $85 \mathrm{~m} / \mathrm{s}$, it only takes $\sim 83 \mathrm{~ns}$ to move one pixel (given a $7 \mu \mathrm{m}$ per pixel resolution). During $1 \mu \mathrm{s}$, a particle would have moved 12 pixels to cause blurring. To help minimize blurring, a high-current short-duration pulsed LED was triggered at a 700 to 900 ns delay after the camera shutter was open. This reduced the effective exposure time to values of 300 to $100 \mathrm{~ns}$, respectively. At $300 \mathrm{~ns}$, the LED provided sufficient light to get good contrast between the particles and background. In $300 \mathrm{~ns}$, particles moving at $85 \mathrm{~m} / \mathrm{s}$ would have moved $\sim 3$ pixels (or $\sim 21 \mu \mathrm{m}$ ) - this distance would be a bias measurement error in the horizontal direction. Data was also taken using a 100 ns delay, which offers less bias error, but the images were darker and consequently had less contrast. 



Figure 14.-High-speed camera and pulsed LED backlight taking particle images during testing (left) and determining the imaged location (focus region) using a laser and graduated glass (right).

The high-speed camera was operated in one of two modes: a particle-counting or particle-velocitymeasurement mode. For particle counting, the objective was to gather a large number of independent images at the same physical location in space ensuring that no particles were counted more than once. In this mode, the camera's full imager $(1280 \times 800$ pixels $)$ was utilized with images taken at $1000 \mathrm{fps}$. Optics resulting in a resolution of $\sim 7 \mu \mathrm{m}$ per pixel were used for this initial testing, although a finer resolution is achievable with different optical components. More specifications for the system in particle counting mode are shown in Table 4 . At the lowest velocities of $85 \mathrm{~m} / \mathrm{s}$, a particle traverses a horizontal distance of $85 \mathrm{~mm}$ in $0.001 \mathrm{sec}$, well in excess of the horizontal FOV of $9 \mathrm{~mm}$, thus ensuring that particles are only counted once in the particle counting mode. A sample image taken while operating the camera in particle-counting mode is shown in Figure 15. The image has been cropped from the original size to $814 \times 542$ pixels for clarity.

An algorithm is currently under development to discriminate between imaged particles that are within the depth of field (i.e., in focus) and those that are outside the depth of field (i.e., out of focus). The algorithm uses an edge-detection filter to identify sharp gradients in the image. A sharp gradient corresponds to an in-focus particle. Currently, various criteria relating the gradient to the degree of focus are being examined. For one such criterion, the resulting in-focus particles are shown in Figure 16 where the perimeter of the in-focus particles is colored in red. Here, several steps are used to identify the in-focus particles including specifying a gradient value and filtering out particles below a certain size. A minimum-detectable particle size, which may be a number like 4 to 6 pixels across a particle, results from the requirement to identify a gradient on both sides of a particle (e.g., 2 to 3 pixels for each edge). At $7-\mu \mathrm{m}$ per pixel, the minimum detectable particle size using the current optics would be 28 to $42 \mu \mathrm{m}$ in diameter. The resulting dataset of particle sizes is being further examined with the goal of calculating statistics on the distribution (i.e., $\mathrm{D}_{\mathrm{V}} 10, \mathrm{D}_{\mathrm{V}} 50$, and $\mathrm{D}_{\mathrm{V}} 90$ ). $\mathrm{A}$ factor affecting those statistics include understanding the relationship between the particle size and depth of field which is needed to calculate the particle concentrations - work is ongoing to develop those relationships for the high-speed camera/LED system.

In particle-velocity-measurement mode, the objective was to capture the same particle in at least 2 consecutive frames so that the distance and hence the velocity of the particle could be measured given the known duration between frames. At a resolution of $7 \mu \mathrm{m}$ per pixel, a particle travelling at $85 \mathrm{~m} / \mathrm{s}$ will traverse the entire horizontal FOV in just over $100 \mu \mathrm{s}$. During that period, a minimum of 2 frames must be imaged which corresponds to a frame rate of just under 20,000 fps. For the March 2012 testing, the camera was operated at $\sim 30,000 \mathrm{fps}$ which allowed measuring particle velocity at the highest test velocity of $135 \mathrm{~m} / \mathrm{s}$. The 30,000 fps was also near the upper limit of the LED pulsing system. At these higher framing rates, only a portion of the imager could be used due to image transfer-time limitations of the camera. It was desired to preserve the horizontal FOV to maximize the potential to image moving particles which traverse in the horizontal plane. Thus, the vertical FOV needed to be cropped to 152 pixels to allow the needed throughput of images at the highest frame rate. The specifications for the system in particle-velocity-measurement mode are summarized in Table 4. 


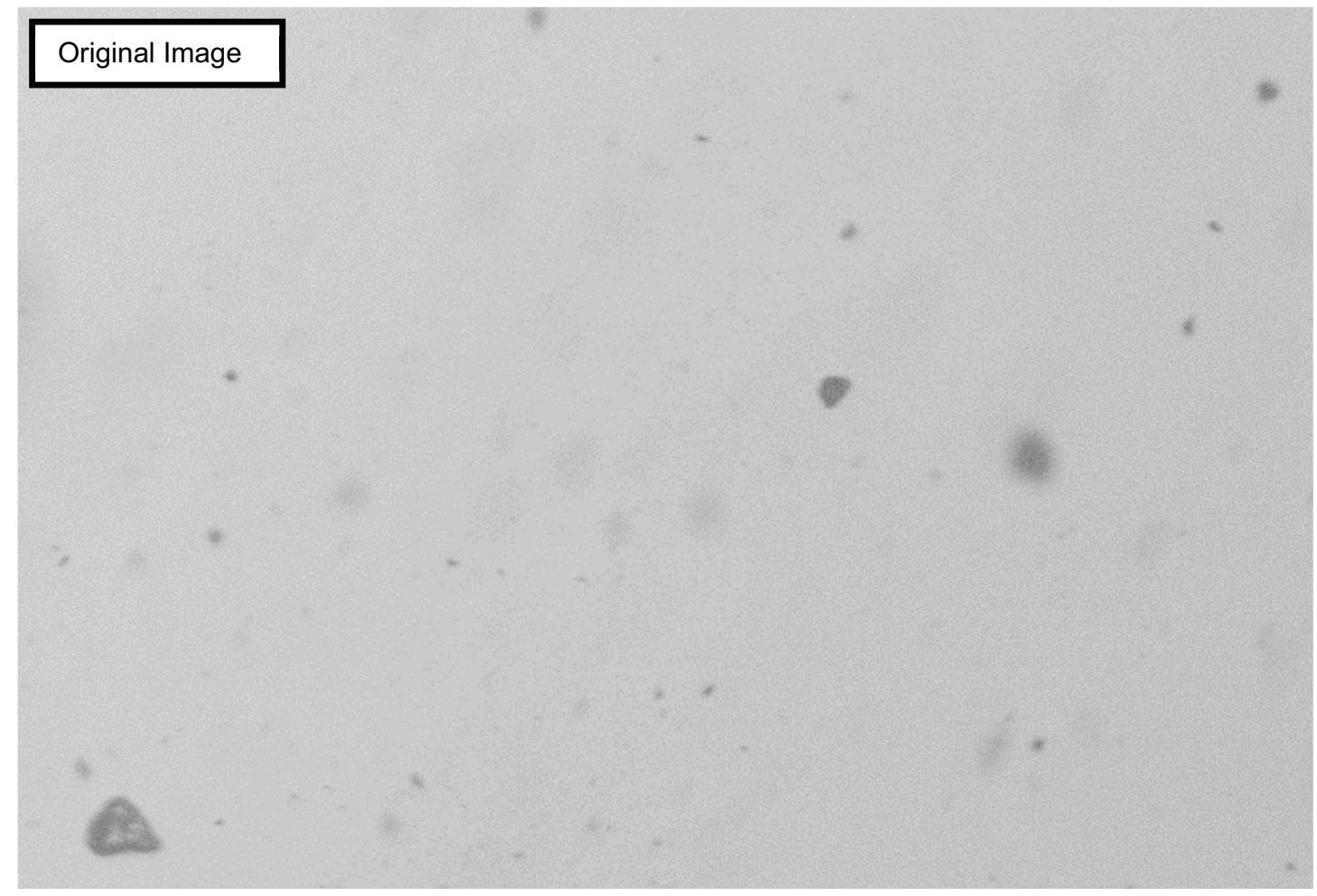

Figure 15.-Sample image of particles taken using the particle counting mode.

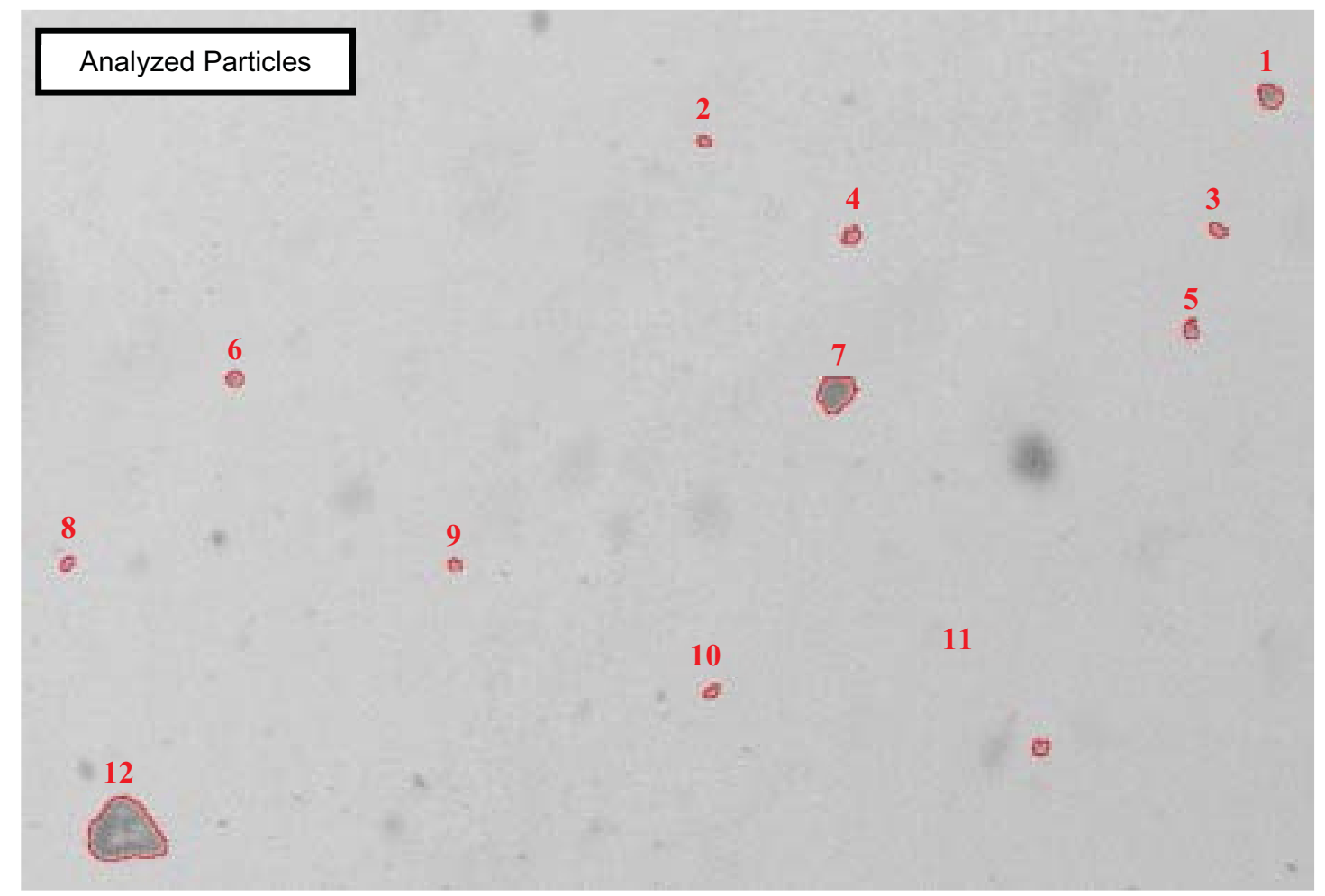

Figure 16.-Particles determined to be in-focus using a developmental algorithm. 
Figure 17.--Images from two consecutive frames captured using a high-speed camera set to capture particle velocity. The time interval between the top and bottom image is of $\sim 33 \mu$ s and the coordinates show the centroid of a particle (in pixels) which moves between the frames.

Figure 17 shows two consecutive frames taken using the particle-velocity-measurement mode. For this test, the camera was sampling at $30010 \mathrm{fps}$ resulting in approximately $33 \mu$ s between images. The centroid of one particle (in pixel coordinates) is shown in both of the images. That particle traversed a horizontal distance of 432 pixels $(3.06 \mathrm{~mm})$ and a vertical distance of 33 pixels $(0.234 \mathrm{~mm})$. This results in velocities of 91.8 and $7.0 \mathrm{~m} / \mathrm{s}$ in the horizontal and vertical directions, respectively. For this particular test (data point 867 ), the average air velocity coming from the ice-injection duct was measured to be 84.1 $\pm 0.5 \mathrm{~m} / \mathrm{s}$ with the cloud-off (the error bars represent the standard deviation of the measurements taken during a 30-sec sample period). Such results could be compared to the cold-jet velocity or perhaps to get local velocity measurements. Additionally, this system could be used to image particles just prior to and during impact onto an icing test article.

\subsection{Conclusions}

In this paper, we describe some cloud-characterization work performed at the NRC RATFac during March and April 2012 in preparation for future scaling studies. The cloud characterization included water content, cloud uniformity, and particle size-spectra measurements. Water content measurements were made using a SEA multi-wire probe. Cloud uniformity measurements came from light scattered from particles passing through a laser sheet normal to the flow. Finally, particle size measurements were made using two developmental shadowgraph systems.

A series of tests examined the SEA multi-wire probe measurements in pure LWC and IWC sprays as well as combined IWC and supplemental LWC sprays, the latter to simulate a "known" mixed phase. LWC-only measurements suggest that the test section liquid water content, $\mathrm{LWC}_{\mathrm{t}}$, can be deduced using the inject water flow rates and measurements of the amount of water that has evaporated. Overall, there is good agreement with the measured $\mathrm{LWC}_{\mathrm{m}}$ values with $\mathrm{LWC}_{\mathrm{t}}$ for all three elements of the SEA multi-wire probe. Applying a similar methodology to an IWC-only cloud showed that the half-pipe element of the SEA multi-wire probe measures approximately half ( $\sim 48.5$ percent) of the IWC at the test section for a tunnel velocity of $85 \mathrm{~m} / \mathrm{s}$ and total pressure of $93 \mathrm{kPa}$. Image data of the front face of the SEA multi-wire probe during testing suggests that not all of the IWC is being evaporated by the half-pipe before being swept away downstream. In addition, data indicates a false response of approximately 4 to 5 percent on the cylindrical hot-wire elements to the fully-glaciated clouds generated in this study.

A hypothesis and analysis algorithm was proposed for interpretation of mixed-phase results using the SEA multi-wire probe which infers the independent $\mathrm{LWC}_{\mathrm{t}}{ }^{*}$ and $\mathrm{IWC}_{\mathrm{t}}{ }^{*}$ (and hence $\mathrm{TWC}_{\mathrm{t}}{ }^{*}$ ) using direct measurements from the probe. The hypothesis asserts that the $\mathrm{LWC}_{\mathrm{m}}$ and $\mathrm{IWC}_{\mathrm{m}}$ measurements superimpose on a non-interference basis allowing use of calibrations from the liquid and ice-only tests. The results were validated by calculating an injected value from $\mathrm{TWC}_{\mathrm{t}}{ }^{*}$ and adding the sublimated and/or evaporated vapor measured by an independent sensor. Note that the individual $\mathrm{IWC}_{\mathrm{t}}{ }^{*}$ and $\mathrm{LWC}_{\mathrm{t}}{ }^{*}$ cannot be independently confirmed because we cannot differentiate contributions of sublimation and evaporation to the total vapor increase measured in the test section during mixed phase. 
Results from the presented data set $(85 \mathrm{~m} / \mathrm{s}, 93 \mathrm{kPa}$, "small” particle size grinder setting) support the hypothesis for values of $\mathrm{TWC}_{\mathrm{t}}$ less than $7.5 \mathrm{~g} / \mathrm{m}^{3}$ but results begin to diverge above this value. The diverging results at larger TWC may suggest that the superposition assumption breaks down once a highenough water loading is achieved. Further testing is required to assess the probe's response at higher water loadings. In addition, other factors may explain some of the disagreement including particle size variations with ambient humidity or test-section non uniformities, neither of which are yet well understood and may affect the calibration curves obtained during single-phase testing. Moreover, only a limited set of data $(85 \mathrm{~m} / \mathrm{s}, 93 \mathrm{kPa}$, "small" particle size $)$, have been explored and additional testing is required to confirm the hypothesis. Finally, the current results use IWC plus supplemental LWC and confirmation of the proposed hypothesis and mixed-phase algorithm still require testing using a mixedphase resulting from melting ice-crystal clouds which is the desired scenario for engine icing. To supplement existing SEA multi-wire traverse data, the uniformity of LWC and IWC clouds were gauged non-intrusively by measuring the scattered light of particles passing through a laser sheet positioned in the test section normal to the flow direction. Plots of the image-average intensity versus $\mathrm{LWC}_{\mathrm{t}}$ and $\mathrm{IWC}_{\mathrm{t}}$ suggest that the measured intensity is a good first-order measurement of concentration, independent of the water phase. Additionally, images of the average intensity across about $1 / 2$ the test section helped visualize the IWC distribution in the test section which showed ellipse-like concentric regions of increasing intensity with the highest counts near the center of the test section for each case. As the $\mathrm{IWC}_{\mathrm{t}}$ increases, greater intensities and steeper intensity gradients are observed in the test section. It is noted that this work is still preliminary and further analysis is on-going.

Two different shadowgraph methods to measure particle size and velocity were used during the 2012 test entry. The first utilized a Particle Imaging Velocimetry (PIV) system and imaged particles in the center of the test section just upstream of where the leading edge of the model would be located (tests were conducted with an empty test section). The second utilized a high-speed camera coupled with a pulsed LED backlight that helped to reduce motion blur by reducing the effective exposure time. Both methods have generated promising image sets that will be processed for size statistics (i.e., $\mathrm{D}_{\mathrm{V}} 10, \mathrm{D}_{\mathrm{v}} 50$, and $\left.D_{V} 90\right)$. A further goal is to quantify any changes in particle size and perhaps state by making particle size measurements at two different downstream locations in the cloud.

The PIV shadowgraphy system was effective in providing good quality images of particles traveling through the test section of the rig and it is these images that will be used to establish particle size distributions and morphology characteristics. The high-speed camera system was operated in one of two modes: one for particle-counting and the other for velocity measurements. An algorithm is currently being developed to discriminate between imaged particles that are within the depth of field (i.e., in focus) and those that are outside the depth of field (i.e., out of focus). The algorithm uses an edge-detection filter which identifies in-focus particles as those with sufficiently sharp gradients. The system is currently able to resolve particles down to $\sim 28 \mu \mathrm{m}$ but could potential resolve smaller particles with different optics. By making two sets of measurements at different downstream locations offers the possibility to discriminate particle phase.

Characterization of the environmental conditions as well as their influence on ice-crystal icing is critical to understanding engine power-loss events. This work, along with previous work both by this group and others, has begun to make strides in understanding the complex environmental conditions leading to ice-crystal icing. However, further work is required to continue cloud characterization in icecrystal and mixed-phase environments. This includes further interpretation of existing results and additional experimental data. The results from this work will help guide future work including scaling studies.

\section{References}

1. Struk, P., Currie, T., Wright, W. B., Knezevici, D. C., Fuleki, D., Broeren, A., Vargas, M., and Tsao, J. "Fundamental Ice Crystal Accretion Physics Studies," SAE 2011 International Conference on Aircraft and Engine Icing and Ground Deicing, 2011-38-0018 or NASA/TM-2012-217429, 2012. 
2. Currie, T. C., Struk, P. M., Tsao, J., Fuleki, D., and Knezevici, D. C. "Fundamental Study of MixedPhase Icing with Application to Ice Crystal Accretion in Aircraft Jet Engines," 4th Atmospheric and Space Environments Conference, AIAA 2012-3035, 2012.

3. Anderson, D. N. "Manual of Scaling Methods," NASA/CR-2004-212875, 2004.

4. Currie, T. C. "Altitude Scaling of Ice Crystal Accretion," 5th AIAA Atmospheric and Space Environments Conference, American Institute of Aeronautics and Astronautics, Reston, VA (submitted for publication).

5. Mason, J. G., Strapp, J. W., and Chow, P. "The Ice Particle Threat to Engines in Flight," 44th AIAA Aerospace Sciences Meeting and Exhibit, AIAA-2006-206, 2006.

6. Bencic, T. "Development of Advanced Optical Instrumentation for use in the NASA Glenn Icing Research Tunnel," 39th Aerospace Sciences Meeting and Exhibit, AIAA-2001-396, 2001.

7. Galeote, B. "Ice Crystal Particle Measurement Using Shadowgraph Imaging Techniques," AIAA Atmospheric and Space Environments Conference, AIAA 2010-7531, 2010.

8. Knezevici, D. C., Fuleki, D., Currie, T. C., and MacLeod, J. D. "Particle Size Effects on Ice Crystal Accretion," 4th AIAA Atmospheric and Space Environments Conference, AIAA 2012-3039, 2012.

9. Lilie, L., Emery, E., Strapp, J. W., and Emery, J. "A Multiwire Hot-Wire Device for Measurment of Icing Severity, Total Water Content, Liquid Water Content, and Droplet Diameter," 43rd AIAA Aerospace Sciences Meeting and Exhibit, AIAA-2005-859, 2005.

10. Van Zante, J. F., Ide, R., and Steen, L.-C. "NASA Glenn Icing Research Tunnel: 2012 Cloud Calibration Procedure and Results," 4th AIAA Atmospheric and Space Environments Conference, AIAA-2012-2933, 2012.

11. Emery, E., Miller, D., Plaskon, S. R., Strapp, J. W., and Lilie, L. "Ice Particle Impact on Cloud Water Content Instrumentation," 42nd Aerospace Sciences Meeting and Exhibit, AIAA-2004-0731 and NASA/TM-2004-212964, 2004.

12. Van Zante, J. F., Addy, H. E., and Ide, R. F. "PSL/Cox Technology Demonstration II, Dec. 2011 Test Summary," NASA Glenn Research Center, Cleveland, OH, 2012 (unpublished).

13. Knezevici, D. C., Fuleki, D., and MacLeod, J. "Development and Commissioning of the Linear Compressor Cascade Rig for Ice Crystal Research,” International Conference on Aircraft and Engine Icing and Ground Deicing, 2011-38-0079, 2011.

14. Papadakis, M., Hung, K. E., Vu, G. T., Yeong, H. W., Bidwell, C. S., Breer, M. D., and Bencic, T. J. "Experimental Investigation of Water Droplet Impingement on Airfoils, Finite Wings, and an S-Duct Engine Inlet," NASA/TM-2002-211700, 2002.

15. Knezevici, D. C., Fuleki, D., Currie, T., Galeote, B., and Chalmers, J. "Particle Size Effects on Ice Crystal Accretion - Part II," 5th AIAA Atmospheric and Space Environments Conference, American Institute of Aeronautics and Astronautics, Reston, VA (submitted for publication). 

